\title{
The INSIEME seismic network: a research infrastructure for studying induced seismicity in the High Agri Valley (southern Italy)
}

\author{
Tony Alfredo Stabile ${ }^{1}$, Vincenzo Serlenga ${ }^{1}$, Claudio Satriano ${ }^{2}$, Marco Romanelli $^{3}$, Erwan Gueguen ${ }^{1}$, \\ Maria Rosaria Gallipoli ${ }^{1}$, Ermann Ripepi ${ }^{1}$, Jean-Marie Saurel ${ }^{4}$, Serena Panebianco ${ }^{1,5}$, \\ Jessica Bellanova ${ }^{1}$, and Enrico Priolo ${ }^{3}$ \\ ${ }^{1}$ Istituto di Metodologie per l'Analisi Ambientale, Consiglio Nazionale delle Ricerche, Tito (PZ), 85050, Italy \\ ${ }^{2}$ Université de Paris, Institut de physique du globe de Paris, CNRS, UMR 7154, 75238 Paris, France \\ ${ }^{3}$ Centro di Ricerche Sismologiche, Istituto Nazionale di Oceanografia e di Geofisica Sperimentale, \\ Sgonico (TS), 34010, Italy \\ ${ }^{4}$ Université de Paris, Institut de physique du globe de Paris, CNRS, UMS 3454, 75238 Paris, France \\ ${ }^{5}$ Università degli Studi della Basilicata, Dipartimento di Scienze, Potenza (PZ), 85100, Italy
}

Correspondence: Tony Alfredo Stabile (tony.stabile@imaa.cnr.it)

Received: 28 June 2019 - Discussion started: 5 July 2019

Revised: 31 January 2020 - Accepted: 4 February 2020 - Published: 4 March 2020

\begin{abstract}
The High Agri Valley is a tectonically active area in southern Italy characterized by high seismic hazard related to fault systems capable of generating up to $M=7$ earthquakes (i.e. the $1857 M_{\mathrm{w}}=7$ Basilicata earthquake). In addition to the natural seismicity, two different clusters of induced microseismicity were recognized to be caused by industrial operations carried out in the area: (1) the water loading and unloading operations in the Pertusillo artificial reservoir and (2) the wastewater disposal at the Costa Molina 2 injection well. The twofold nature of the recorded seismicity in the High Agri Valley makes it an ideal study area to deepen the understanding of driving processes of both natural and anthropogenic earthquakes and to improve the current methodologies for the discrimination between natural and induced seismic events by collecting high-quality seismic data. Here we present the dataset gathered by the INSIEME seismic network that was installed in the High Agri Valley within the SIR-MIUR research project INSIEME (INduced Seismicity in Italy: Estimation, Monitoring, and sEismic risk mitigation). The seismic network was planned with the aim to study the two induced seismicity clusters and to collect a full range of open-access data to be shared with the whole scientific community. The seismic network is composed of eight stations deployed in an area of $17 \mathrm{~km} \times 11 \mathrm{~km}$ around the two clusters of induced microearthquakes, and it is equipped with triaxial weak-motion broadband sensors placed at different depths down to $50 \mathrm{~m}$. It allows us to detect induced microearthquakes, local and regional earthquakes, and teleseismic events from continuous data streams transmitted in real time to the CNR-IMAA Data Centre. The network has been registered at the International Federation of Digital Seismograph Networks (FDSN) with code 3F. Data collected until the end of the INSIEME project (23 March 2019) are already released with open-access policy through the FDSN web services and are available from IRIS DMC (https://doi.org/10.7914/SN/3F_2016; Stabile and INSIEME Team, 2016). Data collected after the project will be available with the permanent network code VD (https://doi.org/10.7914/SN/VD, CNR IMAA Consiglio Nazionale delle Ricerche, 2019) as part of the High Agri Valley geophysical Observatory (HAVO), a multi-parametric network managed by the CNR-IMAA research institute.
\end{abstract}




\section{Introduction}

Anthropogenic seismicity has been documented since the 1920s when the subsidence due to the exploitation of the Goose Creek oil field (USA) was responsible for felt earthquakes (Pratt and Johnson, 1926). Today it is commonly accepted that the term "induced seismicity" is synonymous with anthropogenic seismicity; therefore, in this paper the two terms are considered interchangeable.

Considering the strong socioeconomic impact of induced seismicity (for a complete review see National Research Council, 2013; Ellsworth, 2013; Grigoli et al., 2017; Foulger et al., 2018; Keranen and Weingarten, 2018; Lee et al., 2019), the current research in this field has twofold importance: (a) from a social and economic point of view it is useful for addressing the range of issues related to the induced seismicity, including the development of specific "best practice" protocols, monitoring strategies and traffic light systems, the correct definition of the associated hazard and risk, and the discrimination between natural and induced seismicity; (b) from a purely scientific point of view the research is fundamental for better understanding the processes involved in earthquake generation; the interactions among rock, faults, and fluids as a complex system; and how perturbations of the stress field, even of small size, may affect the stability of faults over time. In order to achieve these two main goals, adequate monitoring networks should be deployed in the study area with the aim to obtain accurate earthquake locations and to lower the completeness magnitude for generating huge microseismic catalogues (Grigoli et al., 2017).

On these grounds, in 2016 a dense seismic network (named INSIEME) was installed in the High Agri Valley (hereinafter HAV), a NW-SE-trending intermontane basin formed during the Quaternary age along the axial zone of the southern Apennines thrust belt chain of Italy (Patacca and Scandone, 1989). Indeed, the area hosts energy technologies that cause two clusters of anthropogenic seismicity. More specifically, one of the two clusters (cluster A in Fig. 1$)$ is continued-reservoir-induced seismicity $\left(M_{1} \leq 2.7\right)$ linked to the seasonal water level fluctuation of the artificial Pertusillo Lake (Valoroso et al., 2009; Stabile et al., 2014a, 2015; Telesca et al., 2015; Vlcek et al., 2018); the other cluster (cluster B in Fig. 1) is fluid-injection-induced seismicity $\left(M_{1} \leq 2\right)$ due to the disposal of the wastewater produced during the exploitation of the biggest onshore oil and gas field in western Europe at the Costa Molina 2 (CM2) injection well (Stabile et al., 2014b; Improta et al., 2015, 2017; Wcisło et al., 2018). Furthermore, the HAV is one of the areas of Italy with the highest seismic hazard with an expected maximum acceleration (referring to average hard ground conditions) for an exceedance probability of $10 \%$ in 50 years within 0.25 and $0.275 \mathrm{~g}$ according to the national reference seismic hazard model (Gruppo di Lavoro MPS, 2004). Indeed the Italian historical seismicity catalogue CPTI11 (Rovida et al., 2011) reports seven earthquakes with $M_{\mathrm{w}} \geq 4.5$ in the HAV, includ- ing the $1857 M_{\mathrm{w}}=7.0$ Basilicata earthquake (Mallet, 1862; Burrato and Valensise, 2008), which was one of the most destructive historical earthquakes in Italy with 11000 casualties and extensive damage throughout the Basilicata, Campania, Apulia, and Calabria regions. It has also been estimated from GPS velocity and strain rate field data (D'Agostino, 2014) that the extensional opening in the axial part of the southern Apennines is about $3 \mathrm{~mm} \mathrm{yr}^{-1}$.

The INSIEME seismic network was designed and developed in the framework of the research project INSIEME (INduced Seismicity in Italy: Estimation, Monitoring, and sEismic risk mitigation), which was funded in 2015 by the SIR (Scientific Independence of young Researchers) programme of the Italian Ministry of Education, Universities and Research (MIUR) and ended on 23 March 2019. Two Italian test sites have been selected for the project's research activities: (a) the Collalto area in the municipality of Susegana (Veneto region, northeastern Italy), a site exploited by Edison Stoccaggio S.p.A. for the storage of natural gas, and (b) the High Agri Valley (Basilicata Region, southern Italy) hosting the biggest onshore oil field in western Europe, managed by Eni S.p.A., and the Pertusillo water reservoir. The Collalto site has already been monitored since 2012 by a dense network of 10 seismic stations and one permanent GNSS geodetic station (https://doi.org/10.7914/SN/EV, Istituto Nazionale di Oceanografia e di Geofisica Sperimentale, 2012), which was the first Italian network providing data with open-access policy (http://oasis.crs.inogs.it, last access: January 2020; as reported in Priolo et al., 2015).

In this paper, we present the INSIEME seismic network and a detailed description of the acquired data which are released through open access. The broadband seismic network has been registered at the International Federation of Digital Seismograph Networks (FDSN, http:// www.fdsn.org, last access: January 2020) with code 3F (https://doi.org/10.7914/SN/3F_2016, Stabile and the INSIEME Team, 2019). Section 2 details the seismic network from its layout to the acquisition, transmission, and preliminary processing of data. Section 3 is focussed on the description of acquired seismic signals from the data quality of continuous data streams to the waveforms of recorded seismic events. Section 4 provides information on data availability. Finally, our discussions and conclusions are reported in Sect. 5.

\section{The INSIEME seismic network}

The INSIEME seismic network has been designed to achieve two main purposes: (a) to study the seismic processes related to the occurrence of events belonging to the two clusters of anthropogenic seismicity and (b) to provide the scientific community with new open-access high-quality seismic data for studying such phenomena and for developing methodologies useful to discriminate between natural and anthro- 


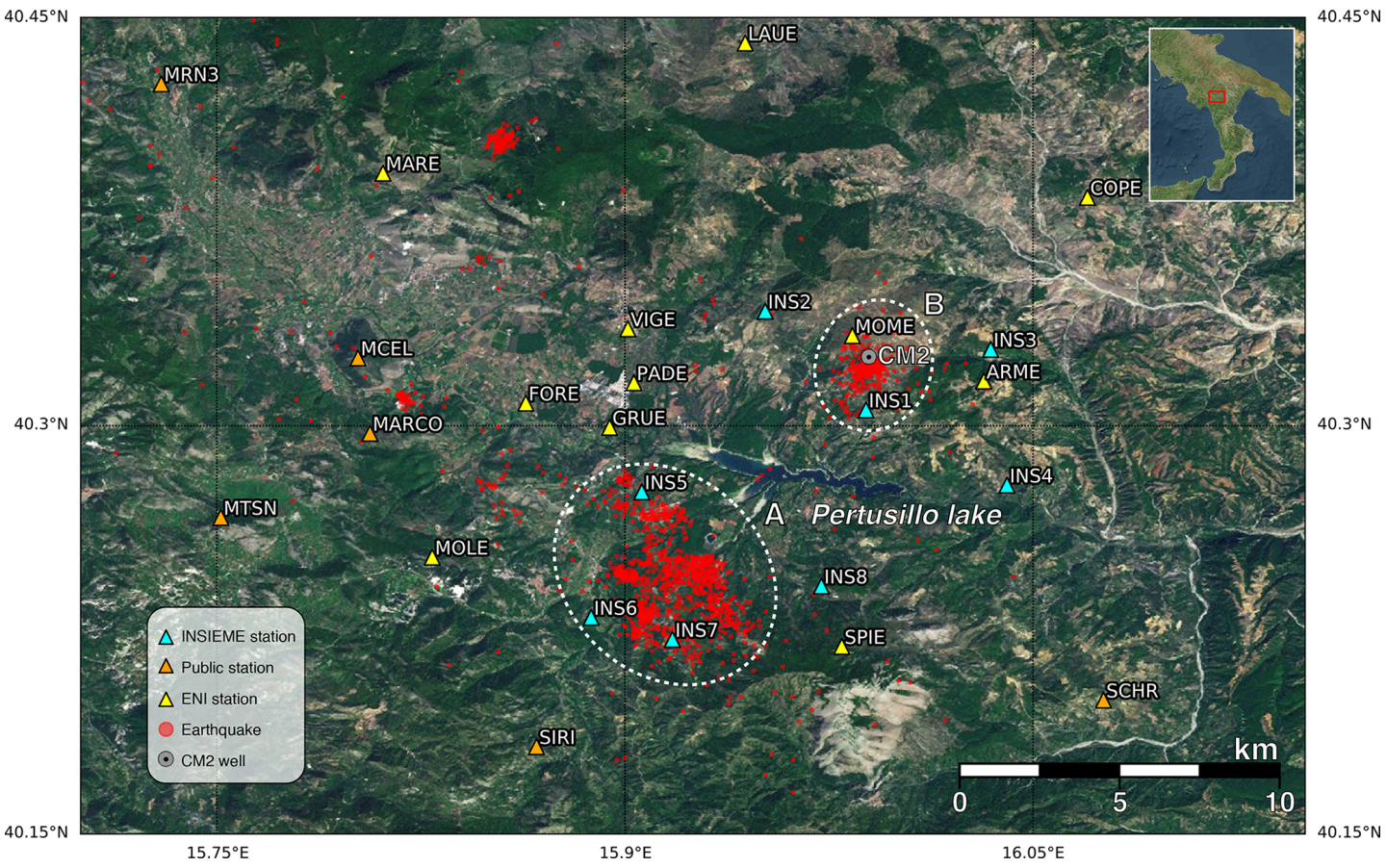

Figure 1. Layout of the INSIEME seismic network in the High Agri Valley. Cyan triangles represent the eight broadband seismic stations of the network. Yellow and orange triangles represent stations belonging to private (i.e. the Eni Company) and public seismic monitoring networks, respectively. The CM2 injection well is depicted with a black dot inside a grey circle. Natural and anthropogenic earthquakes are represented with red circles (2002-2012 seismicity from Serlenga and Stabile, 2019). Anthropogenic seismicity is classified as seismicity induced by continued reservoir (clusters A) and fluid injection (cluster B). The map was drawn using Matplotlib Python library (Hunter, 2007), which incorporates the ArcGIS REST Services freely available at http://server.arcgisonline.com/arcgis/rest/services (last access: January 2020).

pogenic events. The following points provide details of the network from its layout to the data acquisition and processing.

\subsection{Seismic network layout}

The INSIEME network is composed of eight stations covering an area of about $17 \mathrm{~km} \times 11 \mathrm{~km}$, organized in two groups of four stations around each of the two clusters of anthropogenic events (red circles in Fig. 1). All the stations are equipped with broadband sensors installed in non-toxic PVC (polyvinyl chloride) casings at different depths down to $50 \mathrm{~m}$. Network layout and design definition were driven by several constraints, hereafter summarized.

- Seismic stations must be deployed around the two clusters of induced events with as uniform as possible azimuthal distribution.

- Taking into account that the studied clusters are characterized by shallow events of about $4-5 \mathrm{~km}$ focal depth (Serlenga and Stabile, 2019), the epicentral distance of the closest station must be less than the focal depth of events belonging to such seismicity clusters, and the average distance between stations should not exceed twice the event depth (Havskov et al., 2012). These two conditions allow for a good control of event depth estimation.

- High-quality sites, possibly on hard bedrock and therefore without local ground effects, should be selected.

- Recommended station locations must be as far as possible from strong noise sources such as main roads, town centres, industrial, and quarry activities which are largely diffused in the HAV.

- Station sites must be accessible for drilling operations.

- In areas belonging to the national park "Val d'Agri Lagonegrese", which covers large portions of the HAV territory (see file "INSIEME-network.kmz" provided in the Supplement), it is not possible to drill boreholes.

- Station sites should be covered by the $3 \mathrm{G}$ mobile communication link.

- Seismic stations should guarantee continuous data acquisition in all weather conditions, even in the winter season when the snow coverage could reach up to 1.5 $2.0 \mathrm{~m}$ thickness for a couple of weeks. 
- With the aim to provide an effective added value to the seismic monitoring of the HAV, station locations should not overlap existing stations of operating public and private seismic networks.

We performed seismic ambient noise measurements and geological surveys in order to find the most suitable sites according to these constraints, and we verified the access to the site (also for drilling operations of the shallow boreholes), data transmission conditions, and unexpected potential sources of local noise. We evaluated the network performances following the approach proposed by Stabile et al. (2013) by considering different configurations of the potential sites that have met as many constraints as possible. The final network configuration is reported in Fig. 1. It is worth noting that the minimum distance between station (cyan triangles in Fig. 1) ranges between $2.7 \mathrm{~km}$ (INS6 and INS7 stations) and $5.4 \mathrm{~km}$ (INS1 and INS4), the distance of the closest station to each cluster is less than $4-5 \mathrm{~km}$ (the focal depth of induced events), and the INSIEME stations do not overlap stations belonging to other public (orange triangles in Fig. 1) and private (yellow triangles in Fig. 1) seismic networks. Only the INS8 station falls in the national park Val d'Agri - Lagonegrese area and, therefore, the sensor of this station was installed on the surface.

\subsection{Seismic stations}

Considering that the main target of the INSIEME network is to detect and locate the anthropogenic microseismicity in the HAV $\left(M_{1} \leq 2.7\right)$, the seismic stations were equipped with triaxial weak-motion broadband sensors: six $0.05-100 \mathrm{~Hz}$ and two $0.0083-100 \mathrm{~Hz}$ Trillium Compact Posthole (TCPH) seismometers. The data loggers are Centaur digital recorders with a dynamic range of $140 \mathrm{~dB}$. All seismometers and data loggers are manufactured by Nanometrics Inc. (see Table 1). Continuous acquisition of digital waveforms is provided by the INSIEME network at a $250 \mathrm{~Hz}$ sampling rate. This choice allows data acquisition with a Nyquist frequency of $125 \mathrm{~Hz}$ (Fig. 2), which is greater than the upper frequency bound of the broadband sensors $(100 \mathrm{~Hz})$, thus avoiding the application of temporal anti-aliasing filters to the acquired signals and taking advantage of the high-frequency bound provided by the sensors useful to capturing the full spectra content of small earthquakes. The amplitude and phase responses of the two versions of broadband sensors are shown in Fig. 2: blue curves refer to the INS1 station (equipped with a $0.0083-100 \mathrm{~Hz}$ TCPH seismometer) and orange curves refer to the INSX station (equipped with a $0.05-100 \mathrm{~Hz}$ TCPH seismometer). The first installed station of the network was INSX (in operation between 1 April 2016 and 24 January 2017) whereas the other stations have been installed since 23 September 2016 (see Table 2).

With exception of the INS1 station which was initially connected to the electric power grid of the Montemurro

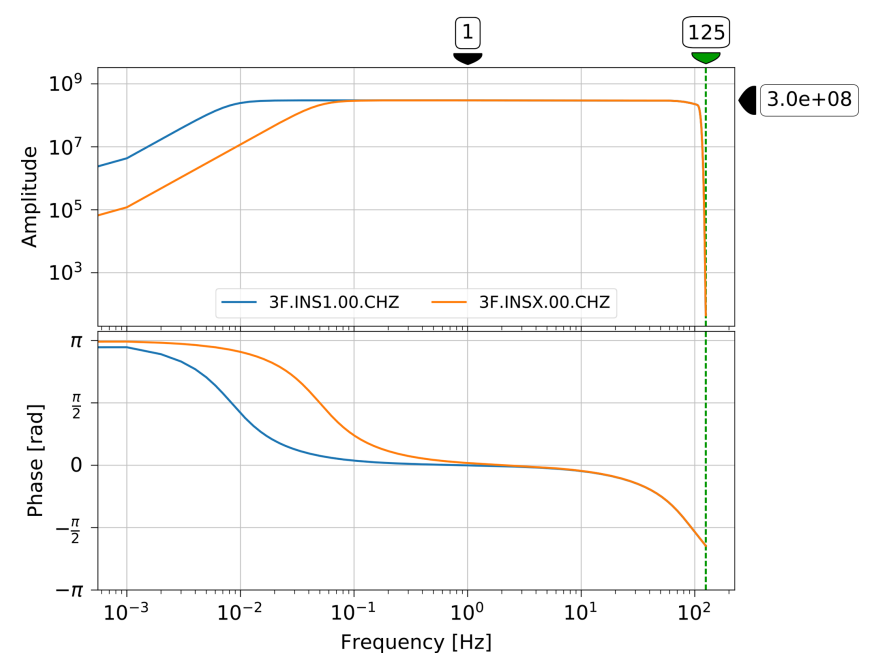

Figure 2. Amplitude and phase response curves for the INS1 station (blue curves), equipped with a $0.0083-100 \mathrm{~Hz}$ TCPH seismometer, and for the INSX station (orange curves), equipped with a 0.05 $100 \mathrm{~Hz}$ TCPH seismometer. The sensor sensitivity at $1 \mathrm{~Hz}$ is also reported. The vertical dotted green line indicates the Nyquist frequency of $125 \mathrm{~Hz}$.

Cemetery, power supply for all stations is provided by solar panels and batteries. Each station is equipped with a $270 \mathrm{~W}$ solar panel and two $12 \mathrm{~V}, 100 \mathrm{Ah}$ batteries connected in series to output $24 \mathrm{~V}$, which allow the instruments to work with less current. Solar panels are installed on $2 \mathrm{~m}$ high poles in order to prevent snow covering during the winter season (see Fig. 3a). The solar charge controller, the two batteries, the power supply circuit, the data logger, and the router are housed in a small cabin (Fig. 3b). Corrugated cables allow the passage of sensor cables from the cabin to the borehole (Fig. 3b). Each borehole is closed by a manhole (Fig. 3b) and the PVC casing is coupled to the soil by cement grout filling the space between the hole and external surface of the PVC casing from the bottom to the surface (Fig. 3c). The PVC casing is not in the manhole in order to leave room for installing sensors on the surface (Fig. 3d). A $2 \mathrm{~m}$ high netting, surrounding an area of about $2.5 \mathrm{~m} \times 2.5 \mathrm{~m}$, protects each station from wild or grazing animals.

The broadband seismometers installed in boreholes are equipped with a coupling system (Fig. 3e), developed by the National Institute of Oceanography and Experimental Geophysics of Italy (OGS), which fastens the sensor to the borehole wall. The inclination of each borehole from the surface to the bottom has been measured with an in-place inclinometer (Jewell Instruments, model 906 "Little Dipper"). We found that the five shallow boreholes of $6 \mathrm{~m}$ depth (stations INS2, INS3, INS4, INS5, and INS6) have inclination at the bottom of less than $1^{\circ}$ and one of the two $50 \mathrm{~m}$ deep boreholes deviates $1.6^{\circ}$ at the bottom (station INS1). Concerning the second $50 \mathrm{~m}$ deep borehole (station INS7), the inclination of the borehole becomes greater than $2^{\circ}$ at depths greater 
Table 1. Geographic coordinates and elevation of the INSIEME broadband seismic stations with indication of the sensor type installed at each station (TCP: Trillium Compact Posthole).

\begin{tabular}{lrrrl}
\hline $\begin{array}{l}\text { Station } \\
\text { name }\end{array}$ & $\begin{array}{r}\text { Latitude } \\
{ }^{\circ} \mathrm{N}\end{array}$ & $\begin{array}{r}\text { Longitude } \\
{ }^{\circ} \mathrm{E}\end{array}$ & $\begin{array}{r}\text { Elevation } \\
\text { (m a.s.1.) }\end{array}$ & $\begin{array}{l}\text { Sensor } \\
\text { type }\end{array}$ \\
\hline INSX & 40.305686 & 15.989105 & 806 & $20 \mathrm{~s}-100 \mathrm{~Hz}$ TCP \\
INS1 & 40.305790 & 15.988603 & 802 & $120 \mathrm{~s}-100 \mathrm{~Hz}$ TCP \\
INS2 & 40.342090 & 15.951559 & 1043 & $20 \mathrm{~s}-100 \mathrm{~Hz}$ TCP \\
INS3 & 40.328033 & 16.034446 & 880 & $20 \mathrm{~s}-100 \mathrm{~Hz}$ TCP \\
INS4 & 40.278168 & 16.040405 & 652 & $20 \mathrm{~s}-100 \mathrm{~Hz}$ TCP \\
INS5 & 40.275704 & 15.906211 & 602 & $20 \mathrm{~s}-100 \mathrm{~Hz}$ TCP \\
INS6 & 40.229581 & 15.887608 & 745 & $20 \mathrm{~s}-100 \mathrm{~Hz}$ TCP \\
INS7 & 40.221487 & 15.917465 & 881 & $120 \mathrm{~s}-100 \mathrm{~Hz}$ TCP \\
INS8 & 40.241083 & 15.972221 & 882 & $20 \mathrm{~s}-100 \mathrm{~Hz}$ TCP \\
\hline
\end{tabular}

Table 2. Position of the broadband sensors during time for each station with the indication of the sensor depth when it is installed in the borehole.

\begin{tabular}{lrr|rr|r}
\hline \multirow{2}{*}{ Station name } & \multicolumn{2}{c|}{ Surface } & \multicolumn{2}{c|}{ Borehole } & Sensor depth \\
\cline { 2 - 5 } & Installation & Uninstallation & Installation & Uninstallation & \\
\hline INSX & $2016-04-01$ & $2017-01-24$ & - & - & - \\
INS1 & - & - & $2016-10-12$ & - & $50 \mathrm{~m}$ \\
INS2 & $2016-09-23$ & $2017-03-22$ & $2017-03-22$ & - & $6 \mathrm{~m}$ \\
INS3 & $2016-08-26$ & $2017-03-22$ & $2017-03-22$ & - & $6 \mathrm{~m}$ \\
INS4 & $2016-08-26$ & $2017-03-22$ & $2017-03-22$ & - & $6 \mathrm{~m}$ \\
INS5 & $2016-08-26$ & $2016-10-13$ & $2016-10-13$ & - & $6 \mathrm{~m}$ \\
INS6 & $2016-08-26$ & $2017-03-22$ & $2017-03-22$ & - & $6 \mathrm{~m}$ \\
INS7 & $2017-03-02$ & $2017-03-23$ & $2017-03-23$ & - & $14 \mathrm{~m}$ \\
INS8 & $2017-03-02$ & - & - & - & - \\
\hline
\end{tabular}

than $20 \mathrm{~m}$. Indeed, at $14 \mathrm{~m}$ depth we measured an inclination of $1.7^{\circ}$, increasing up to $2^{\circ}$ between 16 and $20 \mathrm{~m}$, and over $6^{\circ}$ beyond $24 \mathrm{~m}$ depth. Since the two deeper boreholes host the $0.0083-100 \mathrm{~Hz}$ TCPH seismometers which operate with a maximum tilt of $2^{\circ}$, we installed the seismometer of station INS1 at $50 \mathrm{~m}$ depth whereas the INS7 one was installed at $14 \mathrm{~m}$ depth. Table 2 indicates the sensor depths of each borehole station.

The seismometers at $6 \mathrm{~m}$ depth were installed by a modular non-rotating pipe system developed by OGS in order to control the orientation of the horizontal components (Fig. 3d). The non-rotating system consisted of a set of connectable, light, and rigid pipes, $3 \mathrm{~m}$ long and $50 \mathrm{~mm}$ outside diameter, equipped with a mating joint at the velocimeter end and a reference mark at the top, thus allowing us to push the sensor sled and, at the same time, set the correct azimuthal angle. After the installation was completed we released the joint by lifting and removing the tubes, and the sensor stands were undisturbed. For the two seismometers placed at 14 and $50 \mathrm{~m}$ depth, respectively, the orientation of their horizontal components was unknown because of the impossibility of using a longer non-rotating pipe system. In this case we estimated their azimuthal orientation with respect to a reference station by applying a methodology similar to that proposed by Zheng and McMechan (2006), based on the maximization of the cross-correlation among the horizontal traces of adjacent sensor pairs. Of course, for each pair of adjacent sensors we assume the condition of plane wave approximation which is satisfied if the distance $d$ between sensors is much less than the dominant wavelength $\lambda$ of the recorded signal $(d \ll \lambda)$. Therefore, the signals recorded by the two sensors must be filtered with a cut-off frequency $f_{\mathrm{c}} \ll V d^{-1}$, with $V$ the lowest seismic velocity of the medium.

For each angle $\theta$ ranging from 0 to $360^{\circ}$ with a step size of $0.5^{\circ}$, we computed the normalized cross-correlation between the north component of the signal recorded by the reference station $\left(\mathrm{Sr}_{\mathrm{N}}\right)$ and the first horizontal component of the signal recorded by sensor with unknown orientation and rotated anticlockwise by the angle $\theta\left(\mathrm{Su}_{1}^{\theta}\right)$. In addition, we computed the normalized cross-correlation between the east component of the signal recorded by the reference station $\left(\mathrm{Sr}_{\mathrm{E}}\right)$ and the second horizontal component of the signal recorded by sensor with unknown orientation and rotated anticlockwise by the angle $\theta\left(\mathrm{Su}_{2}^{\theta}\right)$. For each angle $\theta$, the maximum values of the cross-correlation between $\operatorname{Sr}_{\mathrm{N}}$ and $\mathrm{Su}_{1}^{\theta}\left(A^{\theta}\right)$ and between $\mathrm{Sr}_{\mathrm{E}}$ and $\mathrm{Su}_{2}^{\theta}\left(B^{\theta}\right)$ were retrieved. Then, the sensor orienta- 


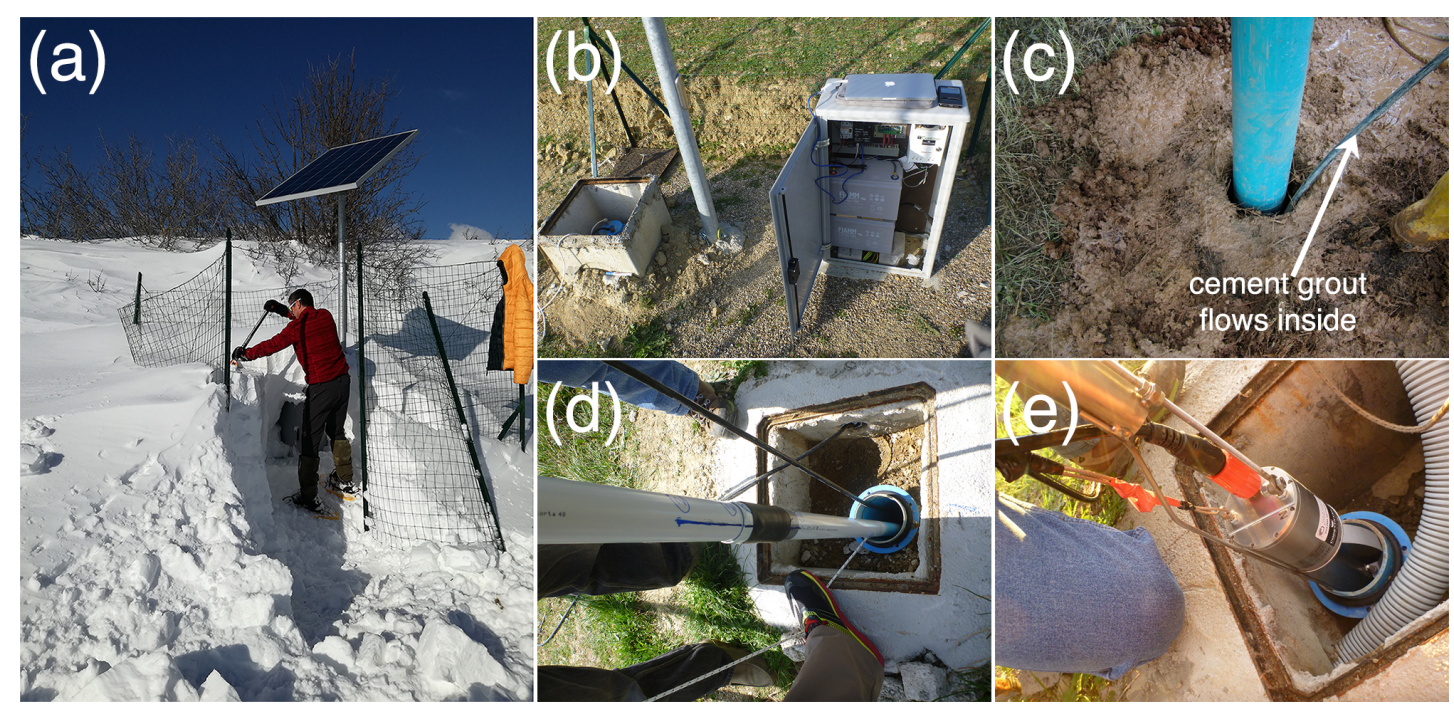

Figure 3. Details of a typical seismic station of the INSIEME network: (a) the solar panel is installed on a pole of $2 \mathrm{~m}$ height in order to prevent it being covered by snow during the winter season; (b) all the instruments of a station are housed in a small cabin which is connected to the borehole where the seismometer is installed inside a PVC casing; (c) the PVC casing is coupled to the soil using cement grout; (d) the PVC casing is not centred in order to leave space for installing sensors on the surface, and seismometers placed at $6 \mathrm{~m}$ depth are installed by using a non-rotating pipe system; (e) all the broadband seismometers installed in boreholes are equipped with a coupling system.

tion with respect to the reference sensor was given by the following Eq. (1):

$\theta^{\mathrm{BEST}}=\theta: \max _{0^{\circ} \leq \theta<360^{\circ}}\left(A^{\theta} B^{\theta}\right)$,

where $\theta^{\mathrm{BEST}}$ is the angle for which the product between $A^{\theta}$ and $B^{\theta}$ is maximum. By applying Eq. (1) over $N$ recordings, we obtained $N$ estimates of $\theta^{\text {BEST}}$; therefore, we evaluated the weighted arithmetic mean and the weighted standard deviation of all the $N$ estimates, with $W_{i}=\left(A^{\theta} B^{\theta}\right)_{i}$ the weight of the $i$ th $\theta_{i}^{\mathrm{BEST}}$.

For station INS1 we used as reference the station INSX, whose sensor was only $70 \mathrm{~m}$ away from the borehole sensor of station INS1. Indeed, both INS1 and INSX were in operation from 12 October 2016 to 24 January 2017 (Tables 1 and 2). We applied a bandpass filter to the seismic recordings with corner frequencies of 0.1 and $0.5 \mathrm{~Hz}$ because we surely satisfy the relation $f_{\mathrm{c}} \ll V d^{-1}$ (i.e. considering that $V_{s}=510 \mathrm{~m} \mathrm{~s}^{-1}$ (Giocoli et al., 2015) and $d=$ $\left.\left(70^{2}+54^{2}\right)^{0.5}=88 \mathrm{~m}\right)$ and because in this frequency range we can also use the seismic ambient noise for determining the rotation angle; in this frequency range, indeed, noise contains the microseismic peak (Longuet-Higgins, 1950) between 4 and $8 \mathrm{~s}(0.125-0.250 \mathrm{~Hz})$, which is very coherent. To compute the rotation angle, we used recordings of three earthquakes $\left(M_{\mathrm{w}}=6.5\right.$ central Italy earthquake of 30 October 2016, $M_{\mathrm{w}}=5.4$ Greece earthquake of 15 October 2016, and $M_{\mathrm{w}}=7.9$ Papua New Guinea earthquake of 22 January 2017) and seismic ambient noise data of different durations ( $20 \mathrm{~min}, 1 \mathrm{~h}$, and $2 \mathrm{~h}$ ). The final estimate of the rotation angle for the sensor of station INS1 is $307.8 \pm 0.4^{\circ}$ anticlockwise to the north.

For station INS7 we used as reference the station INS1 after its alignment to the north because the two stations are both equipped with the same broadband sensors (Table 1). Since 23 March 2017, when the sensor of the INS7 station was installed in the borehole (Table 2), both INS1 and INS7 stations have recorded several teleseismic events. We used the surface waves of 12 selected teleseismic events with $M_{\mathrm{w}} \geq 6.9$ that occurred between November 2017 and $\mathrm{Au}-$ gust 2018 . The distance between stations is $d=11 \mathrm{~km}$; therefore, we applied a low-pass filter to the seismic recordings with a corner frequency of $0.05 \mathrm{~Hz}$ which satisfies the relation $f_{\mathrm{c}} \ll V d^{-1}$ even if we consider a Rayleigh wave speed as low as $2.8 \mathrm{~km} \mathrm{~s}^{-1}$. The final estimate of the rotation angle for the sensor of station INS7 is $43.8 \pm 0.3^{\circ}$ anticlockwise to the north.

\subsection{Seismic data acquisition, data transmission, visualization, and preliminary processing}

Seismic data are transmitted in real time by the $3 \mathrm{G}$ mobile system. The modem-router adopted is Teltonika RUT-500; this device is capable of communicating with every $3 \mathrm{G}$ Italian mobile network and also has an integrated four-port RJ45 $10 / 100 \mathrm{Mbit} \mathrm{s}^{-1}$ Ethernet switch for the local area network. The mobile telecommunication provider allocates a dynamic public IP address to the WAN interface of the router; for this reason the system cannot be continuously reached from an external network, as the address may change. Therefore, it has been configured with a dynamic DNS (domain name sys- 
tem) whose host name is linked up to the router's dynamic IP address. In this way the end user is able to directly reach each seismic station, for both management and data acquisitions.

The use of the dynamic DNS system instead of a VPN system such as OpenVPN was a technical choice because the latter requires a dedicated server and configuration. The dynamic DNS is also supported by other routers already in our warehouse (typically TP-LINK, which does not support VPN) which can temporally replace a Teltonika in case of failure.

The Nanometrics Centaur digital recorder uses a data streaming protocol called SeedLink (https://ds.iris.edu/ds/ nodes/dmc/services/seedlink, last access: January 2020). This is a transmission protocol system used to make the data available on the Internet, based on the "Internet Protocol suite TCP/IP” (Transmission Control Protocol/Internet Protocol) standard.

Since it is not uncommon for routers to encounter problems causing the interruption of the internet connection, each station is equipped with two automatic reboot systems. The first one is integrated inside the router and based on a ping utility: if the system does not ping an external public IP for some time, the router is automatically rebooted. The second one is based on an external programmable time switch which periodically (in our case once a week) unplugs the power supply of the router for a few seconds, thus preventing any software bug that could freeze the Teltonika. When the router restarts, the Centaur data logger is able to send missing data to the CNR-IMAA (National Research Council of Italy, Institute of Methodologies for Environmental Analyses) Data Centre. Despite these precautions, sometimes data gaps may occur due to prolonged temporary absence of the $3 \mathrm{G}$ signal or other minor transmission problems. For this reason, a 16 GB SD memory card is mounted on each Centaur which allows the local storage of about 6 months of data. After a check on data availability using the vertical component data stream of each station for the entire period of operation of the INSIEME seismic network (Fig. 4), the available data range between $93.8 \%$ (INS6 station) and approximately $100 \%$ (INS2, INS3, INS7, and INS8 stations). All the gaps due to transmission problems have been filled by using data saved on each SD memory card. The unfilled gaps are related to a programmed temporary shutdown of a station (e.g. maintenance, firmware update) or to undesired problems occurring at a specific station. As an example, the missing data of station INS6 of about $6.2 \%$ (corresponding to a cumulative time of about 58 out of $940 \mathrm{~d}$ ) are due to a misconfiguration of the solar charge controller on which the night light function was erroneously activated (during sunshine the power was switched off). The problem was understood and definitively solved on 24 January 2017 at 09:52 UTC. After this configuration correction, the gaps at station INS6 have become comparable to those observed at the other stations of the INSIEME seismic network (Fig. 4).
In the CNR-IMAA Data Centre there is a Linux server for data acquisition, storage, and processing. The server has been equipped with a hardware RAID controller (redundant array of independent discs), configured as a "RAID 1" disc mirroring, to protect the data in case of drive failure. Our configuration features two $4 \mathrm{~TB}$ hard discs (i.e. 8 TB RAW space) in RAID 1 mode, ensuring a $N+1$ disc redundancy and a 4 TB total storage capacity. This configuration is an optimal choice for applications requiring high availability. In the future, we will upgrade the system by means of network-attached storage (NAS) in order to store data as well as to enhance the system performance and availability. Furthermore, on this server the TCP/IP-based SeedLink standard compliant SeisComP3 (https://www.seiscomp3.org, last access: January 2020) software runs for seismological data acquisition. It acquires data in real time from the INSIEME stations and neighbour stations, stores them in a miniSEED file structure, and is able to make those data available through various standard protocols: SeedLink for real-time flow, ArcLink (https: //www.seiscomp3.org/doc/applications/arclink.html, last access: January 2020) and FDSN web services (https://www. fdsn.org/webservices, last access: January 2020) for archived data requests. This SeisComP3 software also holds the stations' metadata and an event database. A schematic view of the data flow from the data logger to the data centre is displayed in Fig. 5.

A dedicated web-based system, WebObs (Beauducel et al., 2020), is used to plot a numerical strip chart (called "SefraN") of a representative subset of the configured stations in near real time. SefraN is used to manually identify any event present in the data (Fig. 6, top panels). It is associated with the Daybook, a database of all the events that have been identified in the data, whether they can be located or not, based on the availability of both P- and Swave pickings. Some regional and global events are prefilled with information gathered from INGV (http://terremoti.ingv. it/webservices_and_software, last access: January 2020) and USGS (https://earthquake.usgs.gov/fdsnws/event/1/, last access: January 2020) FDSN event web services. When a new event is identified, the information is sent to the SeisComP3 database (Fig. 6). The event is then manually picked and located (Fig. 6, bottom panel) with SeisComP3 Origin Locator Viewer (scolv), using the 1-D velocity model from Improta et al. (2017). The WebObs Daybook displays the event information collected from the SeisComP3 FDSN web service. A preliminary catalogue of HAV seismicity from September 2016 to March 2019 has been produced and is available at https://doi.org/10.5281/zenodo.3632419 (Stabile et al., 2020). 


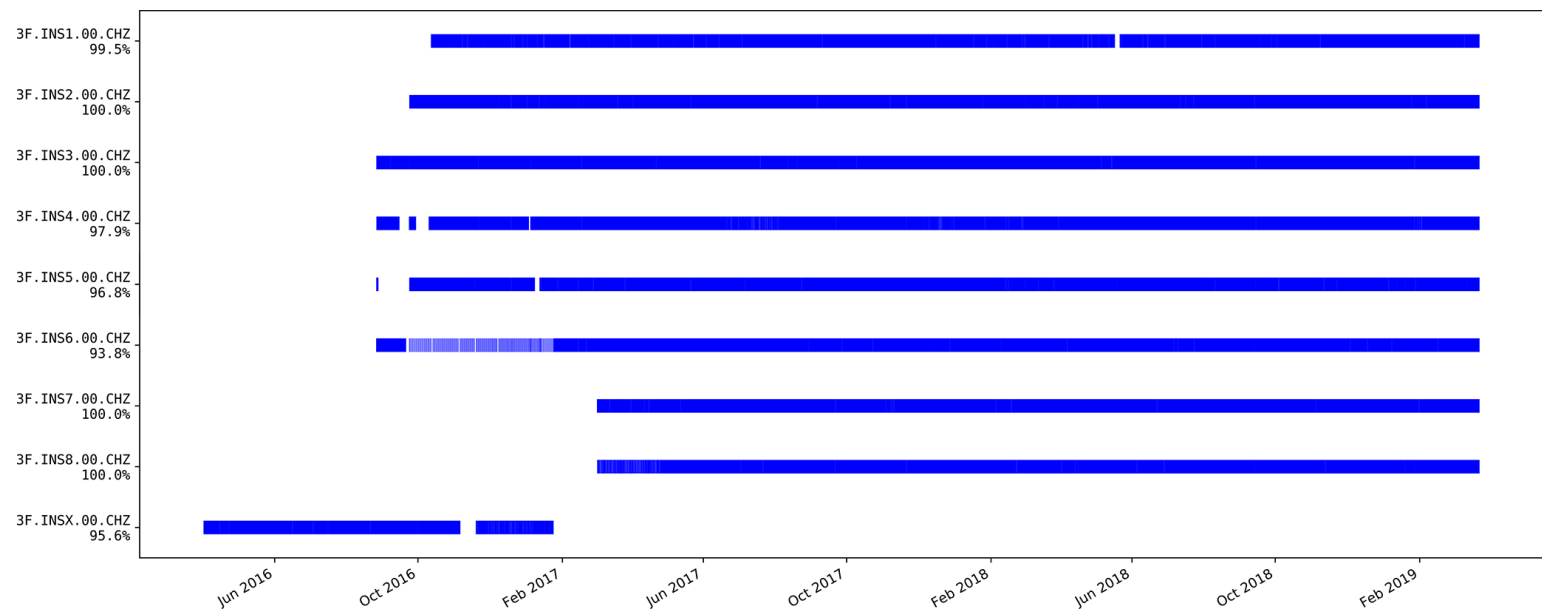

Figure 4. Data availability (blue lines) for all stations for the entire period of operation of the INSIEME seismic network. The analysis has been performed on the vertical component data stream of each station ( $\mathrm{CHZ}$ channels). The percentage of data availability is reported below each station name.

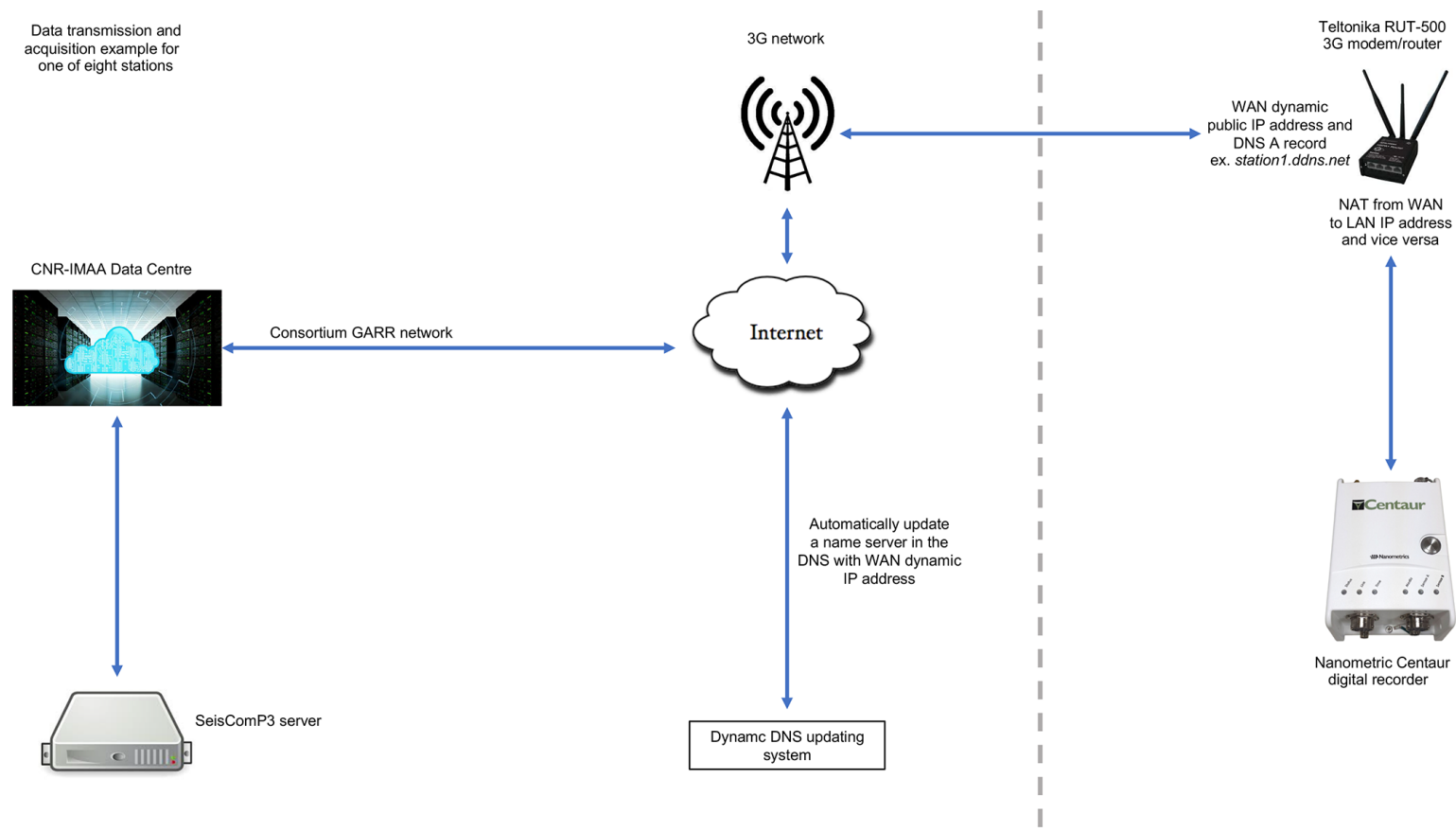

Figure 5. Schematic view of the data flow from the data logger of a remote station to the CNR-IMAA Data Centre.

\section{Acquired seismic signals}

\subsection{Data quality in terms of background noise level}

One of the most important goals of a seismic network is to provide high-quality records of a seismic event from a number of stations as large as possible and with a good azimuthal coverage; therefore, if the seismic noise is high at different sites, the benefits of modern equipment with a large dynamic range are compromised (Havskov et al., 2012).
It is well known that the background noise is due to several factors like temperature changes, weather conditions, and anthropogenic noise. The first two factors generally produce low-frequency noise $(<0.05 \mathrm{~Hz})$ whereas the last usually contains high frequencies $(>1 \mathrm{~Hz})$. In addition there is also the microseismic noise in the range $4-8 \mathrm{~s}$ generated by the sea activity (Longuet-Higgins, 1950). Since most of the broadband sensors of the INSIEME seismic network have a flat response in the range $0.05-100 \mathrm{~Hz}$ (see Table 1) and the seismic network is primarily designed to observe microearthquakes, the main goal of our sensor installations is 


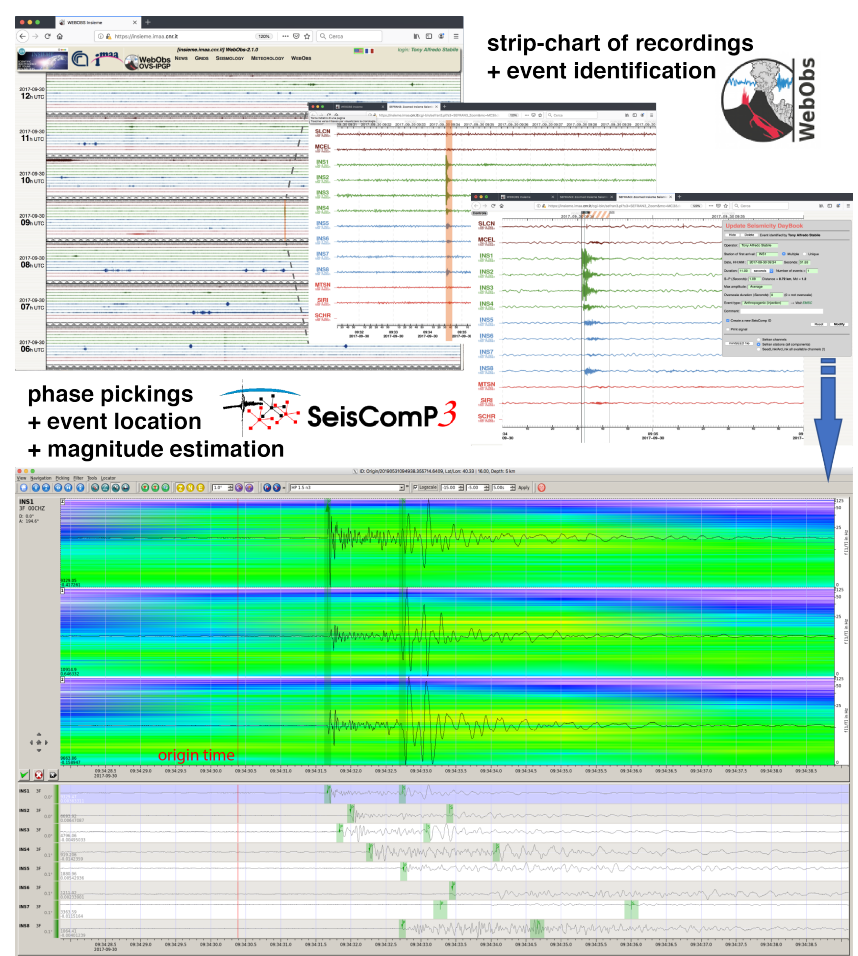

Figure 6. Tools implemented for visualization and processing of acquired seismic data. The WebObs system (top panels) is used to plot a strip chart of recordings at configured stations in near real time for any event present in the data. When an event is identified, the information is sent to the SeisComP3 database for the manual phase picking and event location (bottom panel) through the Origin Locator Viewer tool (scolv).

to attenuate the anthropogenic noise. Several studies have already focused on the attenuation of such a specific kind of noise (Young et al., 1994; Withers et al., 1996) or on the attenuation of the noise over a broader range of frequencies including both low- and high-frequency noise (Hutt et al., 2017). The results of such studies indicate that a successful reduction of the noise is achieved by placing seismic instruments at depth within a rock layer. Indeed, surface layers above the rock, which have low seismic wave velocities, tend to trap the anthropogenic noise and produce site amplification effects. Furthermore, installing seismic sensors at depth in PVC casing has been demonstrated to be an effective way to attenuate the diurnal temperature variation (Spriggs et al., 2014), as we did for our stations.

With the aim to evaluate the seismic noise attenuation at depth for our stations, we first installed the sensors of each station on the surface for a period of about 6 months, and subsequently we moved the sensor inside the PVC casing at depth (Table 2). The only exception is the station INS1 whose sensor was directly installed at $50 \mathrm{~m}$ depth because the surface station INSX was in operation at the same site until 24 January 2017 (Table 2). By selecting continuous data streams acquired by INS1 and INSX stations for $3 \mathrm{~d}$, from
5 to 7 January 2017, characterized by high natural and anthropogenic noise level, we computed the probabilistic power spectral densities (McNamara and Buland, 2004). Figure 7 shows the comparison of the probabilistic power spectral densities (hereinafter PPSDs) obtained for each component of INS1 and INSX stations in the period range 0.01-20 s (frequency range $0.05-100 \mathrm{~Hz}$ ). The colour palette indicates the probability (in percentage) of having a certain noise level as a function of the period. The two grey lines in each panel indicate the new high- and low-noise models, obtained by Peterson (1993), which are used as reference. The two horizontal components of INS1 station ( $\mathrm{CH} 1$ and $\mathrm{CH} 2$, according to the SEED channel naming standard; https://ds.iris.edu/ds/nodes/ $\mathrm{dmc} / \mathrm{data} /$ formats/seed-channel-naming, last access: January 2020) are compared with the two horizontal components of INSX station (CHE and CHN), and the vertical components (CHZ) of the two stations are compared to each other. It is possible to observe that the noise level is less widespread at $50 \mathrm{~m}$ depth than at surface and that for periods below $1 \mathrm{~s}$ (frequencies above $1 \mathrm{~Hz}$ ) we have a reduction of the noise level of about $10 \mathrm{~dB}$ on average and up to $20 \mathrm{~dB}$. In Fig. 7, periods above $20 \mathrm{~s}$ (frequencies below $0.05 \mathrm{~Hz}$ ) are highlighted in grey because in such a period range it is not possible to compare the PPSDs of the two stations since only the sensor of the INS1 station has a flat response up to $120 \mathrm{~s}$ (see Table 1) and, therefore, only its PPSD is significant.

We also computed the PPSD on continuous data streams acquired by the INS1, INS2, and INS4 stations from 26 to 30 December 2017 , a period again characterized by high natural and anthropogenic noise levels. It is possible to note (Table 2) that the INS2 and INS4 stations are equipped with sensors installed at $6 \mathrm{~m}$ depth. Figure 8 shows the comparison among the PPSDs obtained for the horizontal and vertical components of each station in the period range $0.01-20 \mathrm{~s}$ (the sensors of stations INS2 and INS4 are $20 \mathrm{~s}-100 \mathrm{~Hz}$ Trillium Compact Posthole). In this case we do not observe a significant difference of PPSD between a sensor installed at $50 \mathrm{~m}$ depth (as for the INS1 station) and a sensor installed at $6 \mathrm{~m}$ depth (as for the INS2 and INS4 stations); hence we can argue that installing a sensor at $6 \mathrm{~m}$ depth is enough to have a noise reduction in the period range $0.01-20 \mathrm{~s}$ similar to installing a sensor at $50 \mathrm{~m}$ depth.

In order to better understand how the installation of sensors in PVC casing at least $6 \mathrm{~m}$ depth is an effective solution for the seismic noise attenuation, we compared spectrograms over long-time continuous data streams $(41 \mathrm{~d}$ from 2 March and 11 April 2017) acquired by the two seismic stations INS5 and INS6. As evinced in Table 2, the broadband sensor of the INS5 station was installed at $6 \mathrm{~m}$ depth during the whole period of observation; on the other hand, the broadband sensor of INS6 station was first placed on the surface until 22 March 2017 and then moved into the shallow borehole at $6 \mathrm{~m}$ depth. Figure 9 shows the comparison of spectrograms at the two stations over the whole investigated period. The noise attenuation of about $20 \mathrm{~dB}$ at station 


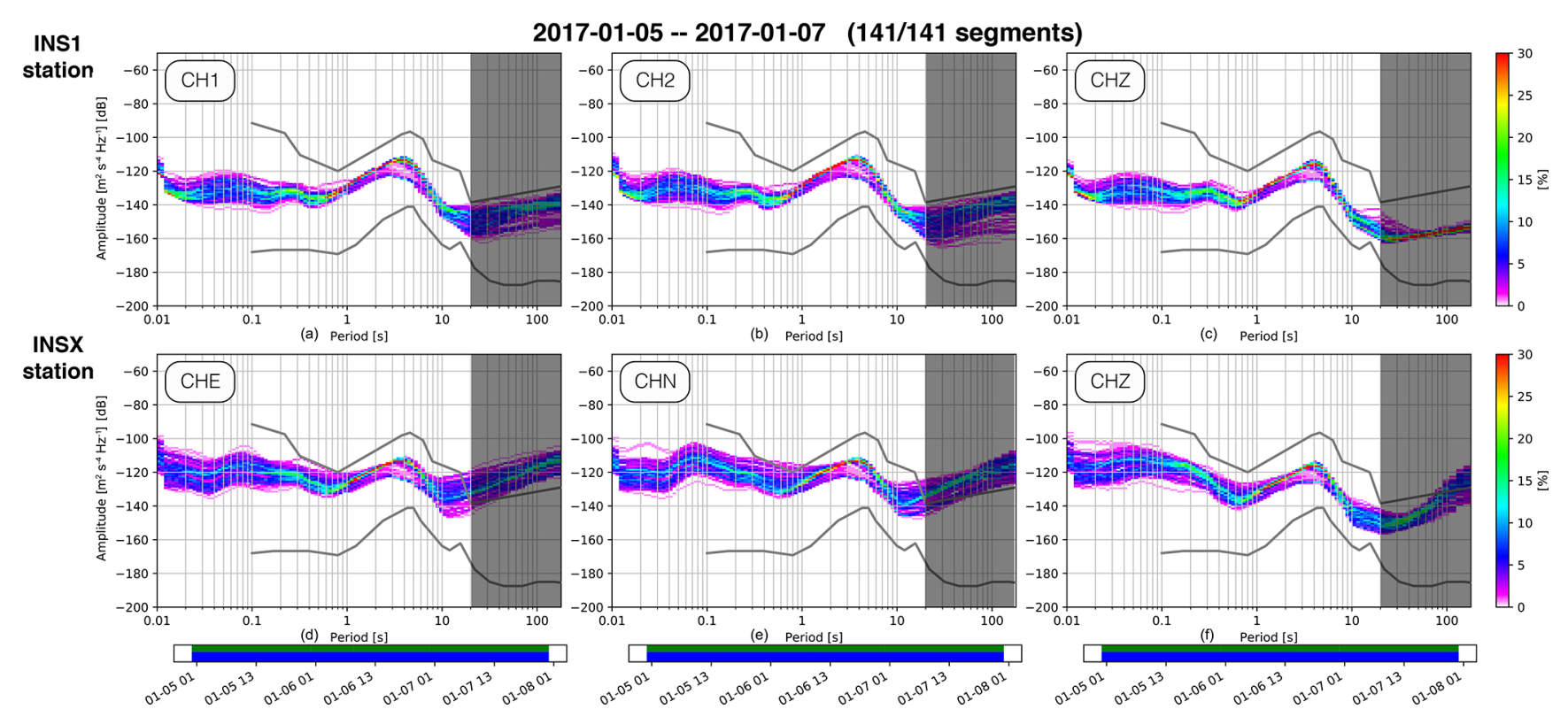

Figure 7. Probabilistic power spectral densities (PPSDs) computed for each component of the station INS1 (a, b, c), with a sensor installed at $50 \mathrm{~m}$ depth, and the station INSX (d, e, f), with a sensor installed at the surface. The colour palettes on the right indicate the probability (in percentage) of having a certain noise level. The two grey curves in each panel indicate the new high- and low-noise models, respectively, obtained by Peterson (1993). Below all PPSD panels the data basis is visualized: the top row is coloured in green for available data and in red (not in this case) for eventual gaps in streams. The bottom row is coloured in blue if the single PSD measurement is included in the PPSD computation. Periods above $20 \mathrm{~s}$ are highlighted in grey because in such a period range it is not possible to compare the PPSD of the two stations (only the sensor of INS1 stations has a flat response up to $120 \mathrm{~s}$ ).

INS5 with respect to station INS6 before 22 March 2017 is very clear, particularly for the two horizontal components, but the noise levels are comparable in the period of time when both stations have their sensors installed at depth. After 22 March 2017 it is possible to observe that the highfrequency $(>1 \mathrm{~Hz})$ day-night succession of INS5 station is a little bit more pronounced than the day-night succession of INS6 station because the former is closer to the urban area of Sarconi town than the latter. Finally, it is interesting to observe, as expected, the increase in the microseismic noise in the range $4-8 \mathrm{~s}$ generated by the sea activity during storms (e.g. in the period 6-9 March 2017 as effects of a strong mistral event in the Tyrrhenian Sea); this phenomenon is masked by the high noise level when the sensors are placed on the surface.

Finally, for a comprehensive analysis of the noise level at the different investigated depths, we computed the PPSD over the entire period of operation of the network for all components of all stations. Figure 10 displays the median values of PPSD for the vertical components (channel CHZ) of sensors installed at different depths and locations. It is worth noting that for frequencies above $1.5 \mathrm{~Hz}$ (periods below $0.6 \mathrm{~s}$ ) the median curves obtained for sensors installed on the surface (black lines in Fig. 10) are generally $10 \mathrm{~dB}$ higher than the median curves obtained for sensors installed at depth (blue, green, and red curves in Fig. 10). The PPSDs computed for each component of each individual station at different depths of the sensor are shown in the Supplement (Figs. S1-S8), which also shows with black curves the 5th, the 55th (median), and the 95th percentiles. The PPSD functions computed over the whole period of operation of the network confirm that the noise level is more widespread when the sensor is installed on the surface with respect to the installation in shallow boreholes (see 95th percentile curves in Figs. S1-S8) and that there is no significant reduction of the noise level for installation of sensors between 6 and $50 \mathrm{~m}$ depth.

\subsection{Data quality in terms of local ground effects}

According to Havskov et al. (2012), local seismic amplifications due to sensor installation on soft ground can greatly affect spectral analyses of low and moderate earthquakes; the use of broadband recordings may become difficult, and the short period signals may be unrepresentative. The absence of meaningful site effects was assessed beforehand for properly choosing the future locations of each seismic station of the INSIEME network. In order to check the validity of our choice and the quality of seismic signals, a further assessment of the negligible site effect on recorded data has been carried out.

To this purpose earthquake data have been selected from the preliminary catalogue of HAV seismicity (https://doi.org/10.5281/zenodo.3632419; Stabile et al., 


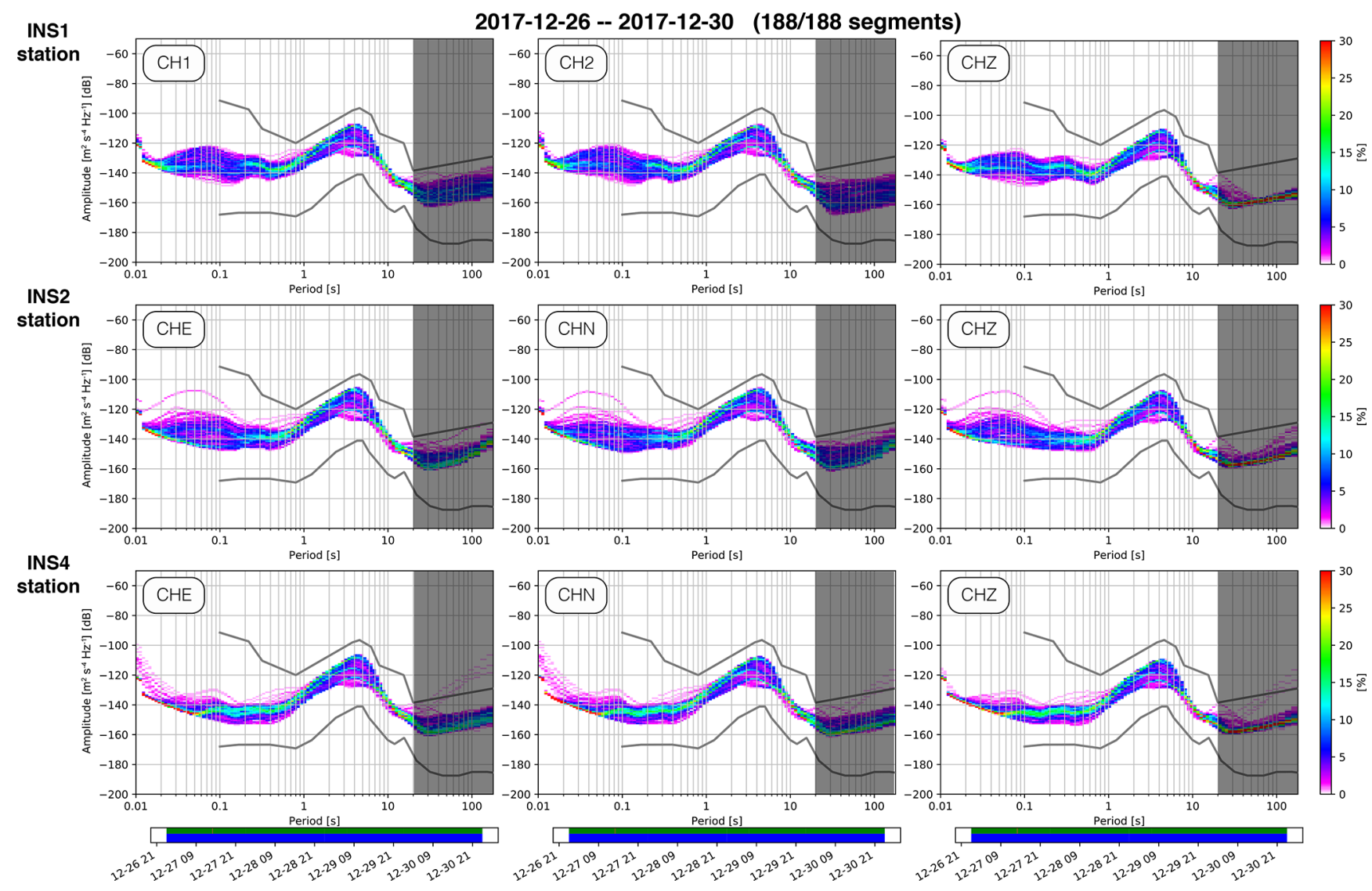

Figure 8. Same type of comparison as Fig. 7 but among stations INS1 (sensor installed at $50 \mathrm{~m}$ depth), INS2 and INS4 (respective sensors both installed at $6 \mathrm{~m}$ depth).

2020). With the aim to have more accurate locations, the events have been relocated by means of NonLinLoc code (Lomax et al., 2000) in a 3-D velocity model of the area (Serlenga and Stabile, 2019), allowing us to better distinguish three different categories of seismic events.

a. The first is injection-induced earthquakes (IIEs hereinafter), whose epicentres belong to the cluster B located NE of the Pertusillo lake and close to the CM2 injection well (see Fig. 1). We also increased the number of IIEs by using a template-matching algorithm based on the cross-correlation processing for single station data proposed by Roberts et al. (1989). In this way we were able to use 164 injection-induced earthquakes.

b. The second is reservoir-induced earthquakes (RIEs hereinafter), belonging to the cluster A located SW of the lake (see Fig. 1), for a total number of 56 events.

c. The third is local earthquakes (LEs hereinafter) located in the HAV. In particular, only events with a magnitude greater than 1.5 were selected, for a total number of 33 events.
In addition to earthquake data, $5 \mathrm{~h}$ of seismic noise data (SN hereinafter) were extracted in the time window 09:0014:00 UTC of 26 November 2018.

In order to assess the presence of possible local ground effects at the sites where the stations were installed, the selected data were analysed by applying the horizontal-tovertical spectral ratio technique (HVSR; Nakamura, 1989), both to earthquakes and to noise data (HVNSR, where the letter "N" stands for "noise").

For this purpose, each component of earthquake data was cut in time windows which allowed us to discard as much as possible the pre- and post-signal noise. For IIE, RIE, and LE data we chose 8,16 , and $32 \mathrm{~s}$ wide time windows, respectively, with a corresponding minimum frequency of 0.125 , 0.0625 , and $0.03125 \mathrm{~Hz}$. In order to have reliable estimates the spectra were evaluated starting from 10 times the respective minimum frequency (i.e. $1.25,0.625$, and $0.3125 \mathrm{~Hz}$ ). The difference in the selected time windows is related to the dissimilar durations of recorded signals of each category of earthquakes. Before computing the fast Fourier transform, the mean and the trend were removed from the time series and signals belonging to any data category were tapered by applying a Tukey window with $5 \%$ bandwidth. Then, the 

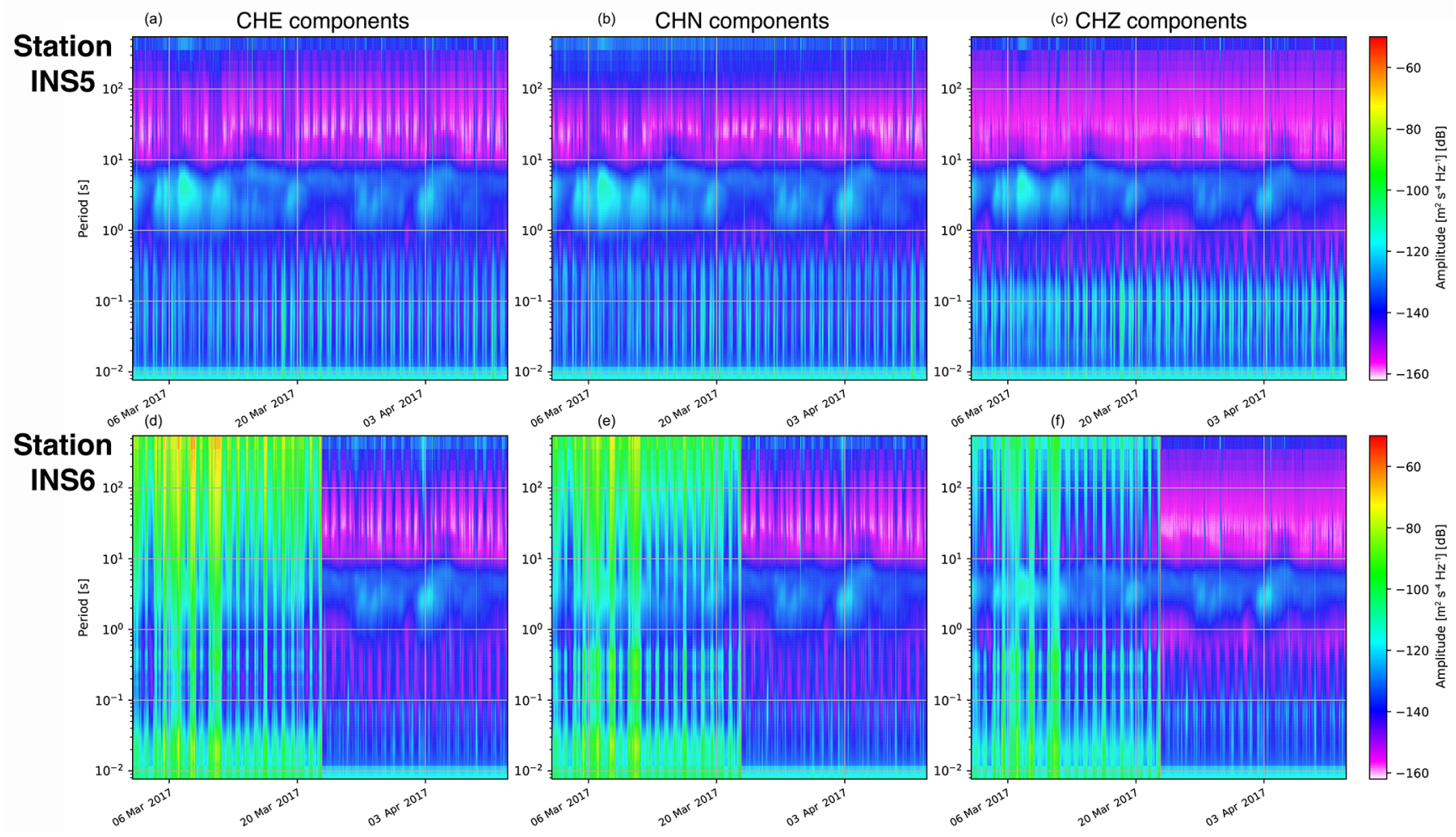

Figure 9. Spectrograms of each component of stations INS5 (a, b, c) and INS6 (c, d, e) computed over continuous data streams of $41 \mathrm{~d}$ (from 2 March to 11 April 2017). The sensor of station INS5 was installed at $6 \mathrm{~m}$ depth for the whole period of observation whereas the sensor of station INS6 was first installed on the surface and then moved at $6 \mathrm{~m}$ depth on 22 March 2017.

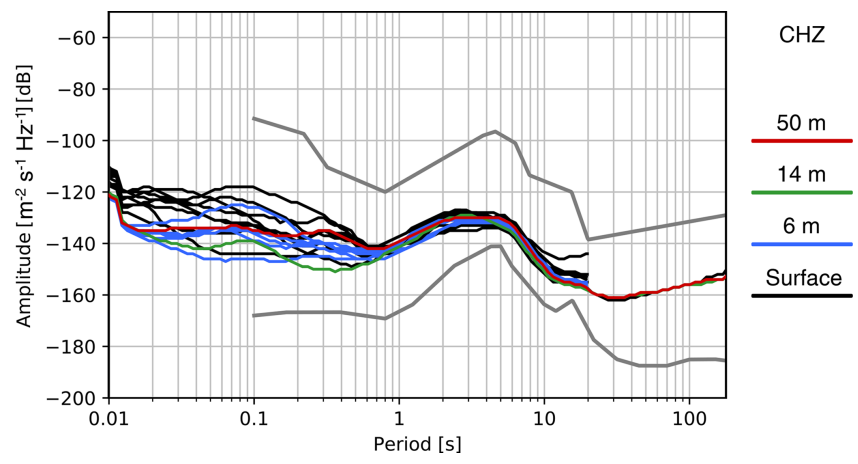

Figure 10. Median values of PPSD computed for the vertical components (channel CHZ) of sensors installed at different depths and locations over the entire period of operation of the INSIEME seismic network. Black curves are the median values of PPSD computed when sensors were installed on the surface; blue, green, and red curves refer to sensors installed at 6,14 , and $50 \mathrm{~m}$ depth, respectively. For sensors with a flat response up to $20 \mathrm{~s}$, the median curves are plotted up to that period. The two grey curves indicate the new high- and low-noise models. computed spectra were smoothed by means of the KonnoOhmachi function (Konno and Ohmachi, 1998), with a bandwidth coefficient equal to 40. The HVSR for each earthquake was retrieved from the arithmetic mean of the horizontal amplitude spectral components (EW and NS) over the vertical amplitude spectral component $(Z)$ of the acquired signal, that is

$\mathrm{HVSR}=\frac{\mathrm{EW}+\mathrm{NS}}{2 Z}$.

Finally, the average HVSR for each station and earthquake category was computed, along with the $\pm 1 \sigma$ ( 1 standard deviation). The choice of performing such an analysis on different types of earthquakes, characterized by a heterogeneous location in space, was related to look for possible source and directivity effects on the consequent HVSR measurements.

The $5 \mathrm{~h}$ long $\mathrm{SN}$ data, on the other hand, were cut in $130 \mathrm{~s}$ wide non-overlapping time windows, which spanned the total temporal extension of the recording, providing a total number of 138 signals with a spectral resolution of $0.007 \mathrm{~Hz}$. The retrieved time series were processed in an analogous way to the one described before for earthquake data by means of the Geopsy software (Geopsy project; http://www.geopsy.org, last access: January 2020). For each time window and station, the HVNSR was retrieved, taking into account that the horizontal spectrum was computed as 

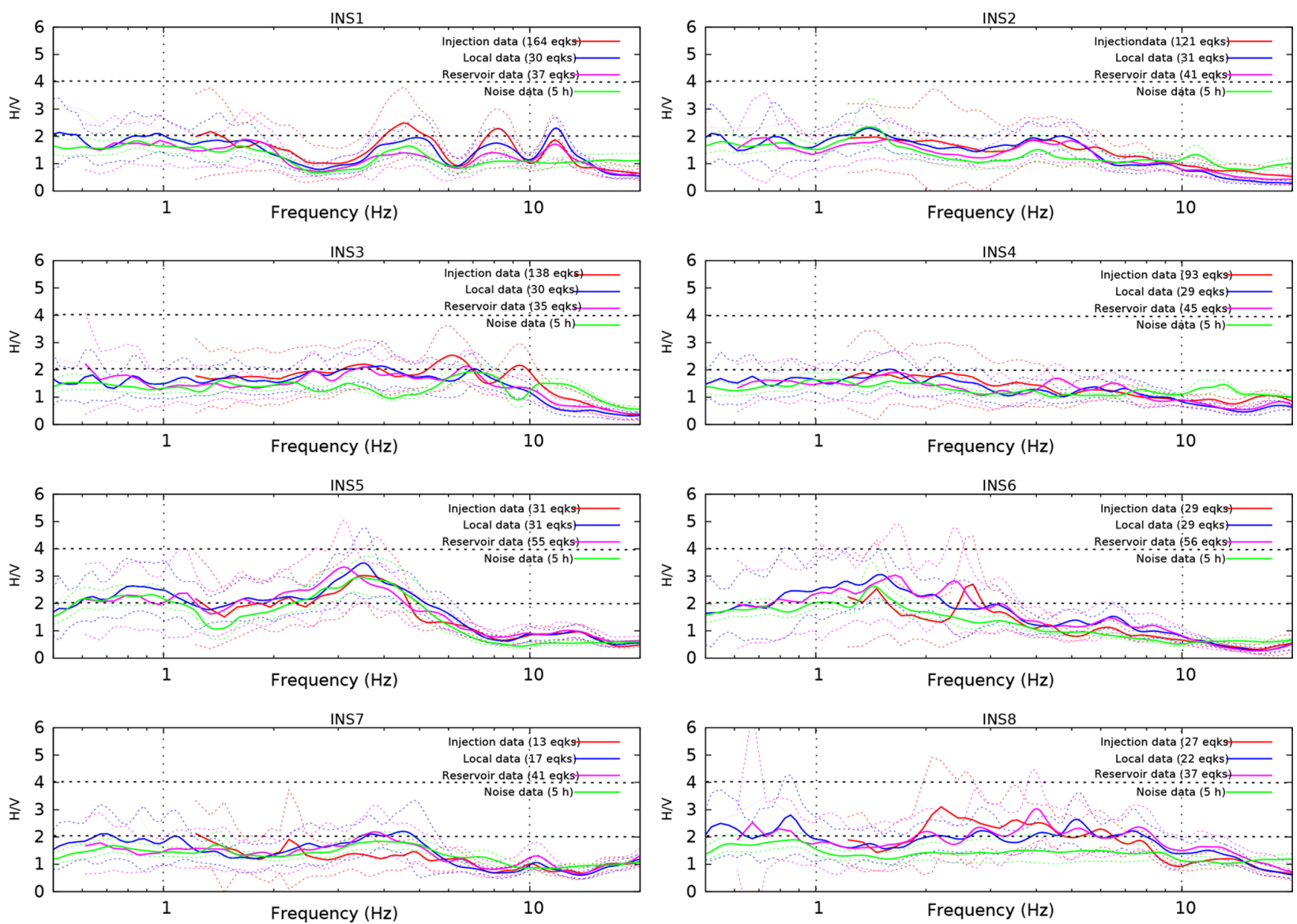

Figure 11. HVSR and HVNSR curves computed at all the INSIEME network seismic stations. For each dataset, the number of used earthquakes and the hours of seismic noise are indicated. The solid coloured lines represent the average HVSR and HVNSR curves, whereas the dashed lines identify the $\pm 1 \sigma$ standard deviations.

the squared average of the two horizontal (EW and NS) components:

$H=\sqrt{\frac{\mathrm{EW}^{2}+\mathrm{NS}^{2}}{2}}$.

Finally, the average HVNSR of each station was computed, along with the $\pm 1 \sigma$.

The retrieved HVSR and HVNSR are represented in Fig. 11. We can assert that most of the stations are characterized by an almost flat $H / V$ curve, independently of the adopted dataset. Furthermore, we separately verified that the choice of an arithmetic mean or a squared average of the two horizontal components is almost completely irrelevant to the consequent HVSR or HVNSR measurements. The arithmetic average adopted for earthquake data analysis allowed us to equally weight possible amplitude peaks related to directivity and azimuthal effects in the HVSR computation. On the other hand, the squared average, which generally overestimates the arithmetic average and which was adopted for analysing the ambient noise data, did not produce higher amplitude peaks: indeed, the retrieved HVNSR curves are flatter than HVSR ones.

In Fig. 11 we observe very low site amplifications, except for the INS5 seismic station, where a relevant peak at about $3.5 \mathrm{~Hz}$ can be noticed and for INS6 whose HVSR function has a slight amplification between 0.8 and $3.0 \mathrm{~Hz}$. Some detailed considerations of the results related to station INS1 must be taken. Previous analyses performed at the same site with ambient noise and earthquake data, by using both a seismometer and an accelerometer located at the surface, and with geological and geophysical (electrical resistivity tomography) surveys allowed us to approximately estimate the depth of the bedrock at about $50 \mathrm{~m}$ (Giocoli et al., 2015). Indeed, an amplitude peak between 2 and $3 \mathrm{~Hz}$ in the retrieved $H / V$ curves was clearly observable. By looking at Fig. 11, this peak is no longer present, confirming that the installation of INS1 at $50 \mathrm{~m}$ depth allowed us to reach a more rigid (higher acoustic impedance) layer; in addition, during perforation operations, a sharp lithological change from alluvial deposits to the Gorgoglione Formation was clearly observed at that depth. At INS1 seismic station, the low-amplitude 
peaks at about $4-5,9$, and $11 \mathrm{~Hz}$ are observed in HVSR curves but not in the HVNSR one. We might interpret these differences as the effect of the down-going earthquake wave field.

\subsection{Induced microearthquakes, local earthquakes, and teleseismic events}

The continuous data acquisition by the INSIEME seismic network allowed us to manually detect, by a visual inspection of recordings through the SefraN tool, a total number of 852 local natural and induced earthquakes between September 2016 and March 2019. Then, these were preliminarily located (https://doi.org/10.5281/zenodo.3632419; Stabile et al., 2020) using the 1-D velocity model by Improta et al. (2017) and Hypo71 algorithm (Lee and Lahr, 1972) embedded in SeisComP3, allowing us to have an initial distinction of the three different categories of seismic events already introduced in the previous section (Sect. 3.2): IIE, RIE, and LE. In order to better locate local events outside the INSIEME network, we build a virtual seismic network composed of 11 seismic stations of the Italian National Seismic Network (FDSN codes: IV, https://doi.org/10.13127/SD/X0FXnH7QfY, INGV Seismological Data Centre, 2006; MN, https://doi.org/10.13127/SD/fBBBtDtd6q, MedNet Project Partner Institutions, 1990) managed by the Italian National Institute of Geophysics and Volcanology (INGV), seven stations belonging to the Irpinia Seismic Network (Weber et al., 2007; Stabile et al., 2013; FDSN code: IX), and MARCO station belonging to the GEOFON network (FDSN code: GE, https://doi.org/10.14470/TR560404, GEOFON Data Centre, 1993), the last installed south of Tramutola town in the framework of a joint scientific cooperation between GFZ Potsdam and CNR-IMAA institutes; all the stations of the virtual network are located within about $60 \mathrm{~km}$ distance from the centre of the INSIEME network.

Here we report the main inferred features for each earthquake category (IIE, RIE, and LE), in terms of both seismic signal properties and hypocentral locations:

a. IIE. A total of 43 injection-induced seismic events were manually picked and located. These were identified because they belong to the seismicity cluster induced by fluid-injection operations at the CM2 well (cluster B in Fig. 1). The first recording station of such events is INS1, which is the closest receiver, with signals characterized by a difference between the arrival times of $\mathrm{S}$ and $\mathrm{P}$ waves of about $1 \mathrm{~s}$. The average depth retrieved from preliminary event location analyses is about $4.5 \mathrm{~km}$ and the maximum recorded local magnitude is $M_{1}=1.4$, related to an induced event that occurred on 29 January 2018 at 15:23:10 UTC (Fig. 12a), located at about $1.4 \mathrm{~km}$ epicentral distance from the INS1 station with a focal depth of about $3.0 \mathrm{~km}$
$\left(M_{1}=1.4\right.$; lat $40.3182^{\circ} \mathrm{N}$, long $15.9842^{\circ} \mathrm{E}$; depth $=$ $3.50 \mathrm{~km}$; from https://doi.org/10.5281/zenodo.3632419, Stabile et al., 2020). Most detected IIEs have a magnitude lower than or equal to 1 ; only two of them are characterized by local magnitude of $M_{1}=1.1$ and $M_{1}=1.4$. Depending on the earthquake energy, the number of stations that recorded the seismic signals changes from a minimum of three for the lowest magnitude event up to 16 , also taking into account stations belonging to the virtual seismic network. The waveforms, usually, have a duration of less than $7 \mathrm{~s}$ at the closest station (INS1), and the highest peak ground velocity amplitude (PGV) measured at that station is about $0.04 \mathrm{~mm} \mathrm{~s}^{-1}$ for the strongest IIE of the catalogue (Fig. 12a).

b. RIE. A total of 117 reservoir-induced seismic events were manually picked and located, in the range $0 \leq$ $M_{1} \leq 1.8$. The P-wave arrivals are usually first detected at the INS5, INS6, or INS7 seismic stations, depending on the earthquake location: indeed, such induced events belong to a wider cluster than IIEs and therefore they are more broadly distributed in the southwestern part of the seismic network (cluster A in Fig. 1). Their average depth is about $4.5 \mathrm{~km}$ and the maximum recorded local magnitude is $M_{1}=1.8$, related to an event that occurred on 2 March 2017 at 21:39:41 UTC (Fig. 12b), located at about $1.9 \mathrm{~km}$ epicentral distance from the INS5 station $\left(M_{1}=1.8\right.$; lat $40.2723^{\circ} \mathrm{N}$, long $15.8840^{\circ} \mathrm{E}$; depth $=$ $4.51 \mathrm{~km}$; from https://doi.org/10.5281/zenodo.3632419, Stabile et al., 2020). Because of the proximity of the stations around this seismicity cluster, RIE earthquakes, in a way similar to IIE, are also characterized by a difference between S- and P-wave arrival times of about $1 \mathrm{~s}$ at the closest station to the epicentre and short duration, less than $8 \mathrm{~s}$ (e.g. see Fig. 12b). The recorded seismic event with the lowest magnitude was detected by seven stations, whereas the strongest earthquake was recorded by 12 stations. Finally, the highest peak ground velocity amplitude recorded up to now for this earthquake category is about $0.08 \mathrm{~mm} \mathrm{~s}^{-1}$ (Fig. 12b).

c. LE. A total of 692 local natural earthquakes were manually picked and located. The main difference with respect to the IIE and RIE is that they are not clustered; they are characterized by a widespread distribution in the investigated area, and their average hypocentral depth of about $10 \mathrm{~km}$ is more similar to the typical depth of Apennines crustal earthquakes. Most recorded LEs are characterized by a local magnitude $<2$ : only 39 seismic events out of 692 have a greater magnitude. Four earthquakes with a magnitude greater than 3 , included in a radius of about $40 \mathrm{~km}$ from the centre of the INSIEME seismic network, have been recorded. The strongest event close to the INSIEME network (epicentral distance of $16 \mathrm{~km}$ 

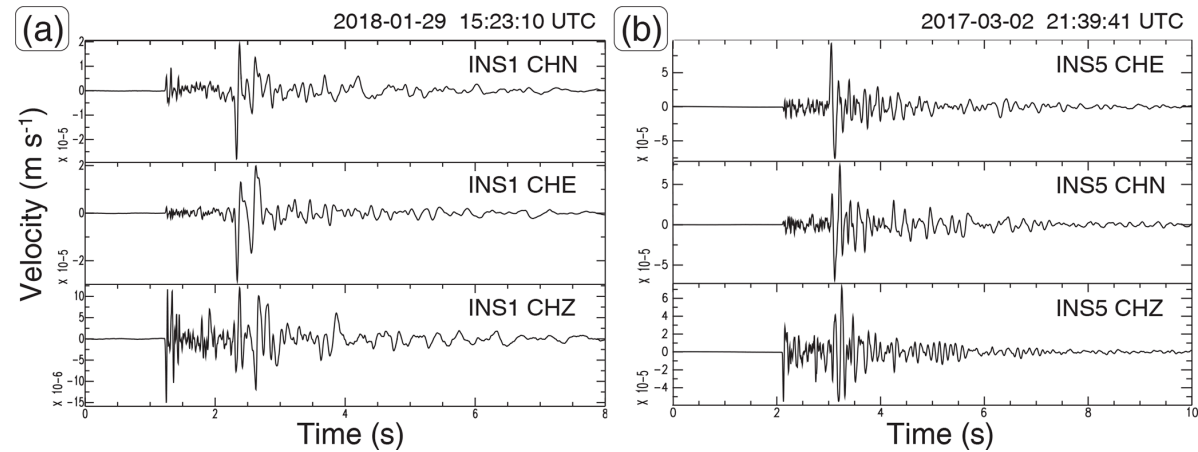

Figure 12. (a) The largest injection induced event $\left(M_{1}=1.4\right.$; lat $40.3182^{\circ} \mathrm{N}$, long $15.9842^{\circ} \mathrm{E}$; depth $\left.=3.50 \mathrm{~km}\right)$ recorded by the INS1 seismic station at $1.4 \mathrm{~km}$ epicentral distance, and (b) the largest reservoir induced event $\left(M_{1}=1.8 ;\right.$ lat $40.2723^{\circ} \mathrm{N}$, long $15.8840^{\circ} \mathrm{E}$; depth $=4.51 \mathrm{~km}$ ) recorded by the INS5 seismic station at $1.9 \mathrm{~km}$ epicentral distance. At the top of the figures the seismic event origin time is reported. For station INS1 the original horizontal components were rotated anticlockwise by an angle of $307.8^{\circ}$ with respect to the north, according to the computations described in detail in Sect. 2.2. A $t_{s}-t_{p}$ of about $1 \mathrm{~s}$ can be clearly noticed for both the injection and the reservoir induced events at the correspondent closest station.

from INS5 and INS6 stations) is a $M_{\mathrm{w}}=3.8$ earthquake (from http://cnt.rm.ingv.it/event/17474201, last access: January 2020). The highest peak ground velocity amplitude of more than $3 \mathrm{~mm} \mathrm{~s}^{-1}$ was recorded at MTSN station, managed by INGV, which was the closest station located at $5 \mathrm{~km}$ epicentral distance. The earthquake was recorded by the whole INSIEME seismic network, as well as by all the stations of the virtual network that were in operation that day (event $M_{1}=4.0$; lat $40.3040^{\circ} \mathrm{N}$, long $15.7200^{\circ} \mathrm{E}$; depth $=12.10 \mathrm{~km}$ reported in https://doi.org/10.5281/zenodo.3632419; Stabile et al., 2020); in Fig. 13 the vertical components of the 18 stations that have recorded the earthquake are displayed.

Concerning teleseismic events, the INSIEME network was able to record the most energetic earthquakes that occurred worldwide in the period in which the analyses have been carried out. In Fig. 14, the recordings at INS1 station of seismic waves generated by the $M_{\mathrm{w}}=7.6$ Chile earthquake of 25 December 2016 are shown. We specifically choose to display the waveforms at INS1 station since it was installed at $50 \mathrm{~m}$ depth and it is a $120 \mathrm{~s}$ instrument: these elements allowed us to clearly see the most important seismic phases generated by the earthquake and by the effects of propagation inside the Earth. Their theoretical arrival times were computed by means of SeisGram2k software (Lomax, 2008), which uses the Preliminary Reference Earth Model (PREM) published by Dziewonski and Anderson (1981). In addition to different seismic phases, in Fig. 14 we are able to observe the dispersive character of surface waves, with lower frequencies, travelling deeper in the Earth and, therefore, faster, arriving at the INS1 station before the higher frequencies.

\section{Data availability}

The INSIEME network has been registered at the International Federation of Digital Seismograph Networks (FDSN), which assigned the network code 3F (2016-2019) (https://doi.org/10.7914/SN/3F_2016; Stabile and the INSIEME Team, 2016). Open-access policy on these data has been adopted under the license CC BY 4.0. Continuous seismic data are available at IRIS DMC from 1 April 2016 to 23 March 2019 (see Fig. 4 illustrating the availability of seismic data for all stations of the network). From IRIS DMC FDSN Web Services (https://service.iris.edu, last access: January 2020) it is possible to download the standard StationXML file (service interface "station") of each station of the network which reports comprehensive information of the station including the instrument response, the time series data in miniSEED and other formats (service interface "datalesect"), and the time series data availability (service interface "availability").

The events preliminarily located with the Origin Locator Viewer (scolv) tool of the SeisComP3 software are available in the "Preliminary catalogue of High Agri Valley seismicity (southern Italy) recorded by the temporary INSIEME network" CSV file (available at https://doi.org/10.5281/zenodo.3632419; Stabile et al., 2020). The KMZ file "INSIEME-network.kmz" (Keyhole Markup language Zipped, which can be viewed using Google Earth), provided in the Supplement, is an interactive extension of Fig. 1 also showing the layout of the virtual network used to preliminarily locate all the events.

Following the end of the SIR-MIUR INSIEME project (23 March 2019), the temporary INSIEME network is going to be updated as a permanent open-access seismic network under the license CC BY 4.0; therefore, acquired data after 23 March 2019 will be available from the permanent 


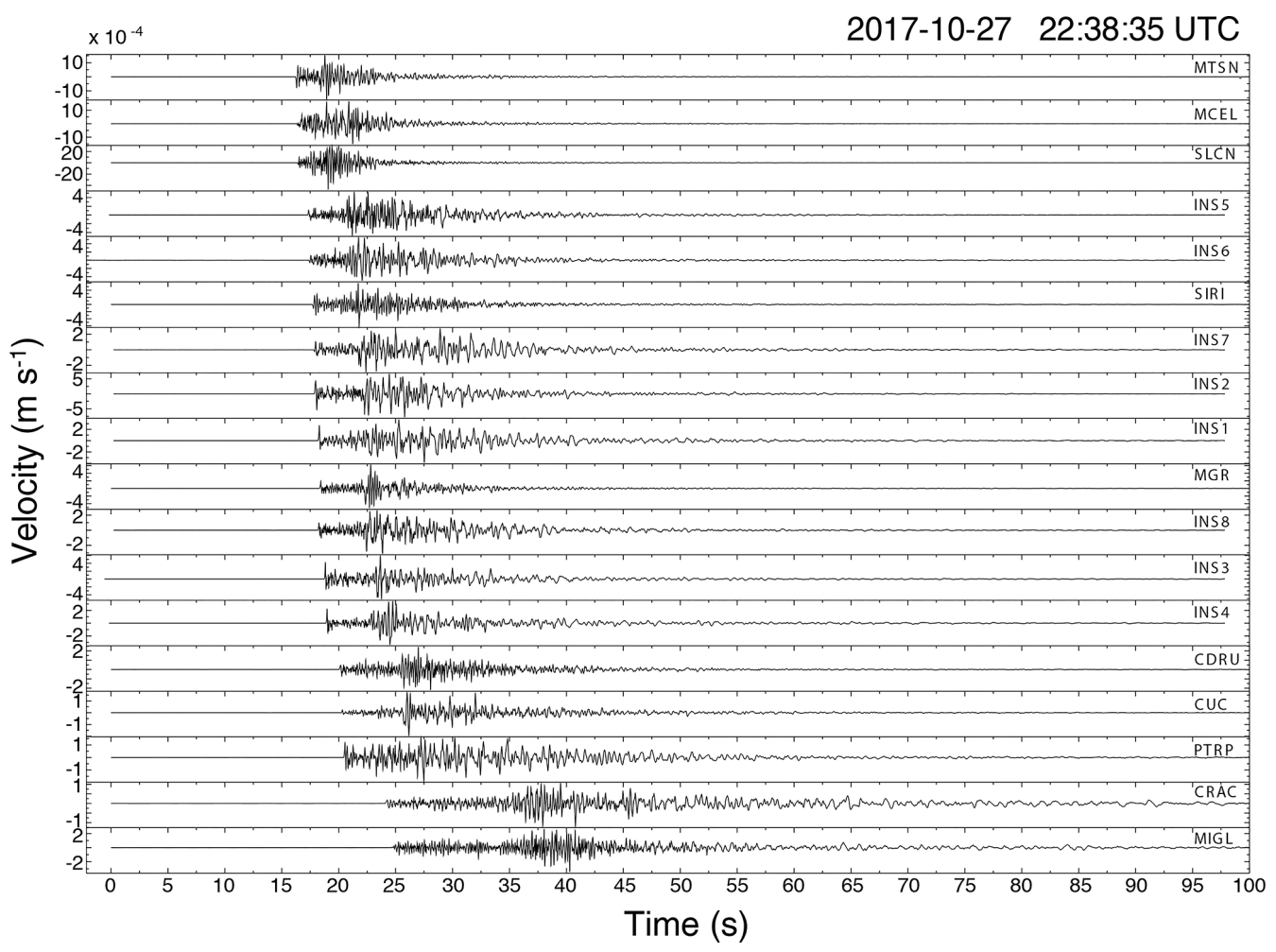

Figure 13. $M_{\mathrm{W}}=3.8$ local earthquake $\left(M_{1}=4.0\right.$; lat $40.3040^{\circ} \mathrm{N}$, long $15.7200^{\circ} \mathrm{E}$; depth $\left.=12.10 \mathrm{~km}\right)$ recorded by the vertical components of the stations belonging to the virtual seismic network composed of INSIEME, INGV, and ISNet seismic stations. The traces are sorted, from top to the bottom, based on the first P-wave arrival time.

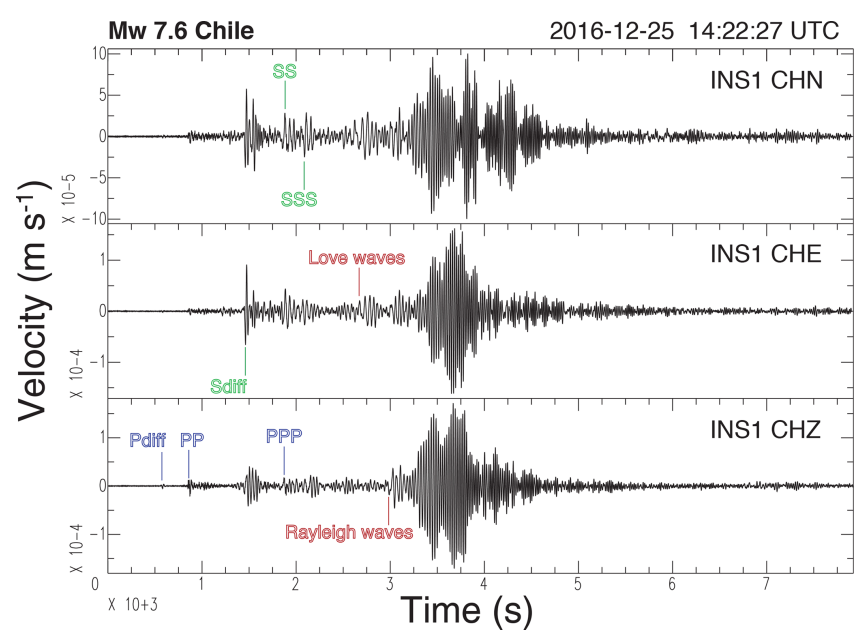

Figure 14. $M_{\mathrm{W}}=7.6$ Chile earthquake of 25 December 2016 recorded by the three components of the INS1 seismic station. At the top right of the figure the origin time of the teleseism is reported. The theoretical arrival times of the most important recorded seismic phases are shown. The original horizontal components were rotated anticlockwise by an angle of $307.8^{\circ}$ with respect to the north, according to the computations described in detail in Sect. 2.2. network with the code VD (https://doi.org/10.7914/SN/VD, CNR IMAA Consiglio Nazionale delle Ricerche, 2019).

\section{Discussion and conclusions}

In this paper we have presented the data collected by the INSIEME seismic network deployed in the HAV to support the research activities of the SIR-MIUR INSIEME project with new high-quality seismic data. Beyond the research purposes of the INSIEME project, we have adopted open-access policy on the continuous data streams acquired by the seismic network since the beginning of data acquisition with the aim to share with the whole scientific community data collected in a very interesting area where both natural and induced events are observed. In this sense, the network can be considered an open-access research infrastructure for studying induced seismicity processes and for developing methodologies for discriminating between natural and induced earthquakes.

All eight stations of the network are equipped with broadband sensors (Table 1), seven of which are installed in PVC casings at different depths down to $50 \mathrm{~m}$ (Table 2). The power supply of stations is provided by solar panels and batteries. Only the INS1 station was initially connected to a power line, but on 14 April 2018 19:16:57 UTC the electric power grid of the Montemurro Cemetery (which powered the station) pre- 
sented voltage and current instability, thus causing a significant disturbance in the seismic signal. After several attempts the problem was definitively bypassed on 29 June 2018, between 07:19 and 10:04 UTC, by also connecting this station to a power system based on solar panels and batteries. The quality of acquired data has been investigated for each station in terms of both the background noise level and the local ground effects. Our analyses indicate that the installation of sensors in PVC casing at $6 \mathrm{~m}$ depth allows a reduction of the noise level up to $20 \mathrm{~dB}$ with respect to the noise level recorded at the surface and that there is not a significant difference in the noise level recorded between 6 and $50 \mathrm{~m}$ depth. Furthermore, all the stations are installed at sites with negligible site amplification, except station INS5 where a relevant amplification is observed at about $3.5 \mathrm{~Hz}$ (Fig. 11).

Between September 2016 and March 2019 we have preliminarily located 852 local natural and induced earthquakes (https://doi.org/10.5281/zenodo.3632419; Stabile et al., 2020): 43 events $\left(M_{1} \leq 1.4\right)$ are classified as IIE, 117 events $\left(M_{1} \leq 1.8\right)$ are classified as RIE, and 692 events $\left(M_{1} \leq\right.$ 4.2) are LE.

The availability of a continuous data stream will give the advantage of applying robust automated data analysis procedures for earthquake detection and location such as the master-event waveform stacking method (Grigoli et al., 2016), the multiband array detection and location method (Poiata et al., 2016), single station (e.g. Roberts at al., 1989) or array (e.g. Gibbons and Ringdal, 2006) template matching algorithms, or the development and testing of new algorithms. As an example, we are developing a single-station template-matching algorithm and we performed a first test by using some IIEs recorded at the INS1 station as event templates, obtaining an additional 135 detections of IIE. In this way it is possible to lower the detection threshold of the seismic network and, consequently, to decrease the magnitude of completeness which leads to the production of a larger microseismic catalogue.

These new seismicity data, hopefully incremented with recordings coming from the stations of the virtual network, could be used for further seismological studies, such as seismic tomography (both elastic and anelastic), comprehensive focal mechanism study of located events (e.g. like the ISC Bulletin published by Lentas et al., 2019), estimation of source parameters of each individual event, detailed earthquake locations to study the space-time evolution of seismicity and for fault imaging, and seismic hazard analyses for a better comprehension of the seismic potential of the area. Continuous data streams can also be used for site characterization studies of the HAV area even for the installation of new stations; in this case some stations of the INSIEME network, particularly the INS4 station, could be used as reference since it has been proven that they are free of site effects (Fig. 11). Besides the IIE, RIE, and LE categories, continuous acquisition allowed us to record teleseisms that occurred worldwide. These data acquired by the broadband sensors of the INSIEME network could integrate the data collected by the Global Seismographic Network (GNS, https://earthquake.usgs.gov/monitoring/gsn, last access: January 2020) or by the GEOFON global seismological broadband network (https://geofon.gfz-potsdam.de, last access: January 2020) for real-time global earthquake monitoring or for global seismology studies. The great coherence of teleseismic recordings provided by such a dense seismic network can also be used as an antenna to track the energy radiated by the propagating rupture along a fault (e.g. Satriano et al., 2014) or, more generally, for seismic array applications (e.g. Gibbons et al., 2008).

In addition to the applications mentioned above, all based on earthquake recordings, continuous data streams also provide large datasets of noise data to be processed for the continuous monitoring of crustal temporal variation in seismic wave speed in the study area (e.g. Clarke et al., 2011) or, alternatively, for obtaining broadband surface wave dispersion curves (Bensen et al., 2007) which could be adopted for ambient noise tomography (e.g. Shapiro et al., 2005) of the HAV.

Finally, it is important to highlight that the INSIEME seismic network will also continue to operate after the end of the SIR-MIUR INSIEME project (23 March 2019) by becoming a permanent open-access seismic network of the High Agri Valley geophysical Observatory (HAVO) managed by the CNR-IMAA research institute.

Supplement. The supplement related to this article is available online at: https://doi.org/10.5194/essd-12-519-2020-supplement.

Author contributions. TAS led the writing of the paper and VS prepared Sect. 3.2 and 3.3. TAS and CS worked on the seismic network layout and on the choice of the acquisition system. MR installed sensors in PVC casing at different depths and evaluated borehole inclination. TAS evaluated sensor orientation and signal quality in terms of noise level. JMS and ER organized the CNR-IMAA Data Centre, including real-time data transmission from the remote stations to the data centre and the installation of software for data processing. EG and TAS performed geological surveys and verified the access to the site, data transmission conditions, and unexpected potential sources of local noise. HVSR and HVNSR analyses were performed by VS and MRG. TAS, VS, JB, and SP manually picked the seismic phases and located the natural and anthropogenic seismic events. All co-authors provided comments which contributed to the paper.

Competing interests. The authors declare that they have no conflict of interest.

Acknowledgements. The authors would like to thank the mayors of the municipalities that host the seismic stations of the IN- 
SIEME network for their authorizations: Senatro Di Leo (Montemurro), Cesare Marte (Sarconi), Antonio Maria Imperatrice (Grumento Nova), Amedeo Cicala (Viggiano), Franco Curto (Armento), and Mario Solimando (Spinoso). Figures 1, 2, 4, 7, 8, 9, 10, and S1-S8 were drawn using the Matplotlib (Hunter, 2007) and/or ObsPy (Beyreuther et al., 2010) Python libraries. Figures 12, 13, and 14 were drawn using the Seismic Analysis Code (Goldstein et al., 2003).

Financial support. This research has been supported by the INSIEME project of the Italian SIR-MIUR programme (grant no. RBSI14MN31).

Review statement. This paper was edited by Kirsten Elger and reviewed by two anonymous referees.

\section{References}

Beauducel, F., Lafon, D., Béguin, X., Saurel, J.-M., Bosson, A., Mallarino, D., Boissier, P., Brunet, C., Lemarchand, A., Anténor-Habazac, C., Nercessian, A., and Fahmi, A. A.: WebObs: The Volcano Observatories Missing Link Between Research and Real-Time Monitoring, Front. Earth Sci., 8, 48, https://doi.org/10.3389/feart.2020.00048, 2020.

Bensen, G. D., Ritzwoller, M. H., Barmin, M. P., Levshin, A. L., Lin, F., Moschetti, M. P., Shapiro, N. M., and Yang, Y.: Processing seismic ambient noise data to obtain reliable broad-band surface wave dispersion measurements, Geophys. J. Int., 169, 12391260, https://doi.org/10.1111/j.1365-246X.2007.03374.x, 2007.

Beyreuther, M., Barsch, R., Krischer, L., Megies, T., Behr, Y., and Wassermann, J.: ObsPy: A Python Toolbox for Seismology, Seismol. Res. Lett., 81, 530-533, https://doi.org/https://doi.org/10.1785/gssrl.81.3.530, 2010.

Burrato, P. and Valensise, G.: Rise and Fall of a Hypothesized Seismic Gap: Source Complexity in the Mw 7.0 16 December 1857 Southern Italy Earthquake, B. Seismol. Soc. Am., 98, 140-144, https://doi.org/10.1785/0120070094, 2008.

Clarke, D., Zaccarelli, L., Shapiro, N. M., and F. Brenguier, F.: Assessment of resolution and accuracy of the Moving Window Cross Spectral technique for monitoring crustal temporal variations using ambient seismic noise, Geophys. J. Int., 186, 867882, https://doi.org/10.1111/j.1365-246X.2011.05074.x, 2011.

CNR IMAA Consiglio Nazionale delle Ricerche (Italy): High Agri Valley geophysical Observatory, International Federation of Digital Seismograph Networks, Dataset/Seismic Network, https://doi.org/10.7914/SN/VD, 2019.

D'Agostino, N.: Complete seismic release of tectonic strain and earthquake recurrence in the Apennines (Italy), Geophys. Res. Lett., 41, 1155-1162, https://doi.org/10.1002/2014GL059230, 2014.

Dziewonski, A. M. and Anderson, D. L.: Preliminary Earth Reference Model, Phys. Earth Planet. In., 25, 297-356, https://doi.org/10.1016/0031-9201(81)90046-7, 1981.

Ellsworth, W. L.: Injection-induced earthquakes, Science, 341, 1225942, https://doi.org/10.1126/science.1225942, 2013.
Foulger, G. R., Wilson, M. P., Gluyas, J. G., Julian, B. R., and Davies, R. J.: Global review of humaninduced earthquakes, Earth-Sci. Rev., 178, 438-514, https://doi.org/10.1016/j.earscirev.2017.07.008, 2018.

GEOFON Data Centre: GEOFON Seismic Network, Deutsches GeoForschungsZentrum GFZ, Germany, https://doi.org/10.14470/TR560404, 1993.

Gibbons, S. J. and Ringdal, F.: The detection of low magnitude seismic events using array-based waveform correlation, Geophys. J. Int., 165, 149-166, https://doi.org/10.1111/j.1365246X.2006.02865.x, 2006.

Gibbons, S. J., Ringdal, F., and Kværna, T.: Detection and characterization of seismic phases using continuous spectral estimation on incoherent and partially coherent arrays, Geophys. J. Int., 172, 405-421, https://doi.org/10.1111/j.1365246X.2007.03650.x, 2008.

Giocoli, A., Stabile, T. A., Adurno, I., Perrone, A., Gallipoli, M. R., Gueguen, E., Norelli, E., and Piscitelli, S.: Geological and geophysical characterization of the southeastern side of the High Agri Valley (southern Apennines, Italy), Nat. Hazards Earth Syst. Sci., 15, 315-323, https://doi.org/10.5194/nhess-15-3152015, 2015.

Goldstein, P., Dodge, D., Firpo, M., and Minner, L.: SAC2000: Signal processing and analysis tools for seismologists and engineers, in: The IASPEI International Handbook of Earthquake and Engineering Seismology, edited by: Lee, W. H. K., Kanamori, H., Jennings, P. C., and Kisslinger, C., Academic Press, London, 2003.

Grigoli, F., Cesca, S., Krieger, L., Kriegerowski, M., Gammaldi, S., Horalek, J., and Dahm, T.: Automated microseismic event location using Master-Event Waveform Stacking, Sci. Rep., 6, 25744 , https://doi.org/10.1038/srep25744, 2016.

Grigoli, F., Cesca, S., Priolo, E., Rinaldi, A. P., Clinton, J. F., Stabile, T. A., Dost, B., Fernandez, M. G., Wiemer, S., and Dahm, T.: Current challenges in monitoring, discrimination, and management of induced seismicity related to underground industrial activities: A European perspective, Rev. Geophys., 55, 310-340, https://doi.org/10.1002/2016RG000542, 2017.

Gruppo di Lavoro MPS: Redazione della mappa di pericolosità sismica prevista dall'Ordinanza PCM 3274 del 20 marzo 2003, Rapporto Conclusivo per il Dipartimento della Protezione Civile, INGV, Milano-Roma, 65 pp., 2004.

Havskov, J., Ottemöller, L., Trnkoczy, A., and Bormann, P.: Seismic Networks, in: New Manual of Seismological Observatory Practice (NMSOP-2), IASPEI, edited by: Bormann, P., GFZ German Research Centre for Geosciences, chap. 8, 65 pp., https://doi.org/10.2312/GFZ.NMSOP-2_CH8, 2012.

Hunter, J. D.: Matplotlib: A 2D graphics environment, IEEE Comput. Sci. Eng. 9, 90-95, https://doi.org/10.1109/MCSE.2007.55, 2007.

Hutt, C. R., Ringler, A. T., and Gee, L. S.: Bull. Broadband seismic noise attenuation versus depth at the Albuquerque Seismological Laboratory, B. Seismol. Soc. Am., 107, 1402-1412, https://doi.org/10.1785/0120160187, 2017.

Improta, L., Valoroso, L., Piccinini, D., and Chiarabba, C.: A detailed analysis of wastewater-induced seismicity in the Val d'Agri oil field, Italy, Geophys. Res. Lett., 42, 2682-2690, https://doi.org/10.1002/2015GL063369, 2015.

Improta, L., Bagh, S., De Gori, P., Valoroso, L., Pastori, M., Piccinini, D., and Buttinelli, M.: Reservoir structure 
and wastewater-induced seismicity at the Val d'Agri oilfield (Italy) shown by three-dimensional $\mathrm{Vp}$ and $\mathrm{Vp} / \mathrm{Vs}$ local earthquake tomography, J. Geophys. Res.-Sol. Ea., 122, 9050-9082, https://doi.org/10.1002/2017JB014725, 2017.

INGV Seismological Data Centre: Rete Sismica Nazionale (RSN), Istituto Nazionale di Geofisica e Vulcanologia (INGV), Italy, https://doi.org/10.13127/SD/X0FXNH7QFY, 2006.

Istituto Nazionale di Oceanografia e di Geofisica Sperimentale: Collalto Seismic Network - Rete Sismica di Collalto, International Federation of Digital Seismograph Networks, Dataset/Seismic Network, https://doi.org/10.7914/SN/EV, 2012.

Keranen, K. M. and Weingarter, M.: Induced Seismicity, Annu. Rev. Earth Pl. Sc., 46, 149-174, https://doi.org/10.1146/annurevearth-082517-010054, 2018.

Konno, K. and Ohmachi, T.: Ground-motion characteristic estimated from spectral ratio between horizontal and vertical components of micro-tremor, B. Seismol. Soc. Am., 88, 228-241, 1998.

Lee, K.-K., Ellsworth, W. L., Giardini, D., Townend, J., Ge, S., Shimamoto, T., Yeo, I.-W., Kang, T.-S., Rhie, J., Sheen, D.-H., Chang, C., Woo, J.-U., and Langenbruch, C.: Managing injection-induced seismic risks, Science, 364, 730-732, https://doi.org/10.1126/science.aax1878, 2019.

Lee, W. H. K. and Lahr, J. C.: HYPO71 (revised): A Computer Program for Determining Hypocenter, Magnitude, and First Motion Pattern of Local Earthquakes, Geol. Surv., Open-File Rep. (U.S.), 75-311, 1972.

Lentas, K., Di Giacomo, D., Harris, J., and Storchak, D. A.: The ISC Bulletin as a comprehensive source of earthquake source mechanisms, Earth Syst. Sci. Data, 11, 565-578, https://doi.org/10.5194/essd-11-565-2019, 2019.

Lomax, A: SeisGram2K-Seismogram visualization and analysis software for the Internet-Ver5.3, available at: http://alomax.free. $\mathrm{fr} /$ seisgram/SeisGram2K.html (last access: June 2014), 2008.

Longuet-Higgins, M. S.: A theory of the origin of microseisms, Philos. T. R. Soc. Lon., 243, 1-35, 1950.

Lomax, A., Virieux, J., Volant, P., and Berge, C.: Probabilistic earthquake location in 3-D and layered models: Introduction of a Metropolis-Gibbs method and comparison with linear locations, in: Advances in seismic event location, edited by: Thurber, C. H. and Rabinowitz, N., Amsterdam, Kluwer, 101-134, 2000.

Mallet, R.: The great Neapolitan earthquake of 1857, The first principles of observational seismology, Chapman and Hill, London, England, vol. I, 431 pp., vol. II, 399 pp., 1862

McNamara, D. E. and Buland, R. P.: Ambient noise levels in the continental United States, B. Seismol. Soc. Am., 94, 1517-1527, https://doi.org/10.1785/012003001, 2004.

MedNet Project Partner Institutions: Mediterranean Very Broadband Seismographic Network (MedNet), Istituto Nazionale di Geofisica e Vulcanologia (INGV), Italy, https://doi.org/10.13127/SD/FBBBTDTD6Q, 1990.

Nakamura, Y.: A method for dynamic characteristics estimation of subsurface using microtremor on the ground surface, Quart. Rep. Jpn. Railway Tech. Res. Inst. (RTRI), 30, 25-33, 1989.

National Research Council: Induced Seismicity Potential in Energy Technologies, The National Academies Press, Washington, DC, 262 pp., 2013.

Patacca, E. and Scandone, P.: Post-Tortonian mountain building in the Apennines: The role of the passive sinking of a relic litho- spheric slab, in: The lithosphere in Italy: advances in earth science research, edited by: Boriani, A., Bonafede, M., Piccardo, G. B., and Vai, G. B., Atti Conv. Lincei, 80, 157-176, 1989.

Peterson, J.: Observations and Modeling of Seismic Background Noise, U.S. Geological Survey Open-File Report 93-322, 1993.

Poiata, N., Satriano, C., Vilotte, J. P., Bernard, P., and Obara, K.: Multiband array detection and location of seismic sources recorded by dense seismic networks, Geophys. J. Int., 205, 15481573, https://doi.org/10.1093/gji/ggw071, 2016.

Pratt, W. E. and Johnson, D. W.: Local subsidence of the Goose Creek oil field (Texas), B. Seismol. Soc. Am., 34, 577-590, 1926.

Priolo, E., Romanelli, M., Plasencia Linares, M. P., Garbin, M., Peruzza, L., Romano, M. A., Marotta, P. Bernardi, P., Moratto, L., and Zuliani, D.: Seismic monitoring of an underground natural gas storage facility: The Collalto Seismic Network, Seismol. Res. Lett., 86, 109-123, https://doi.org/10.1785/0220140087, 2015.

Roberts, R. G., Christoffersson, A., and Cassidy, F.: Real-time event detection, phase identification and source location estimation using single station three-component seismic data, Geophys. J. Int., 97, 471-480, https://doi.org/10.1111/j.1365246X.1989.tb00517.x, 1989.

Rovida, A., Camassi, R., Gasperini, P., and Stucchi, M.: CPTI11, la versione 2011 del catalogo Parametrico dei Terremoti Italiani, INGV, Milano, Bologna, Italy, https://doi.org/10.6092/INGV.ITCPTI11, 2011.

Satriano, C., Dionicio, V., Miyake, H., Uchida, N., Vilotte, J.-P., and Bernard, P.: Structural and thermal control of seismic activity and megathrust rupture dynamics in subduction zones: Lessons from the Mw 9.0, 2011 Tohoku earthquake, Earth Planet. Sc. Lett., 403, 287-298, https://doi.org/10.1016/j.epsl.2014.06.037, 2014.

Serlenga, V., and Stabile, T. A.: How do Local Earthquake Tomography and inverted dataset affect earthquake locations? The case study of High Agri Valley (Southern Italy), Geomat. Nat. Haz. Risk, 10, 49-78, https://doi.org/10.1080/19475705.2018.1504124, 2019.

Shapiro, N. M., Campillo, M., Stehly, L., and Ritzwoller, M. H.: High-Resolution Surface wave Tomography from Ambient Seismic Noise, Science, 307, 1615-1618, https://doi.org/10.1126/science.1108339, 2005.

Spriggs, N., Bainbridge, G., and Greig, W.: Comparison study between vault seismometers and posthole seismometers, EGU General Assembly, Geophys. Res. Abstr., 16, EGU2014-6441, EGU General Assembly 2014, Vienna, Austria, 2014.

Stabile, T. A. and the INSIEME Team: SIR-MIUR Project INSIEME - broadband seismic network in Val d'Agri (southern Italy), International Federation of Digital Seismograph Networks, Dataset/Seismic Network, https://doi.org/10.7914/SN/3F_2016, 2016.

Stabile, T. A., Iannaccone, G., Zollo, A., Lomax, A., Ferulano, M. F., Vetri, M. L. V., and Barzaghi, L. P.: A comprehensive approach for evaluating network performance in surface and borehole seismic monitoring, Geophys. J. Int., 192, 793-806, https://doi.org/10.1093/gji/ggs049, 2013.

Stabile, T. A., Giocoli, A., Lapenna, V., Perrone, A., Piscitelli, S., and Telesca, L.: Evidences of low-magnitude continued reservoir-induced seismicity associated with the Pertusillo artificial lake (southern Italy), B. Seismol. Soc. Am., 104, 1820-1828, https://doi.org/10.1785/0120130333, 2014a. 
Stabile, T. A., Giocoli, A., Perrone, A., Piscitelli, S., and Lapenna, V.: Fluid injection induced seismicity reveals a NE dipping fault in the southeastern sector of the High Agri Valley (southern Italy), Geophys. Res. Lett., 41, 5847-5854, https://doi.org/10.1002/2014GL060948, 2014b.

Stabile, T. A., Giocoli, A., Perrone, A., Piscitelli, S., Telesca, L., and Lapenna, V.: Relationship between seismicity and water level of the Pertusillo reservoir (southern Italy), Boll. Geof. Teor. Appl., 56, 505-517, https://doi.org/10.4430/bgta0161, 2015.

Stabile, T. A., Serlenga, V., Satriano, C., Romanelli, M., Gueguen, E., Gallipoli, M. R., Ripepi, E., Saurel, J.-M., Panebianco, S., Bellanova, J., and Priolo, E.: Preliminary catalogue of High Agri Valley seismicity (southern Italy) recorded by the temporary INSIEME network (Version 1.0), Data set, Zenodo, https://doi.org/10.5281/zenodo.3632419, 2020.

Telesca, L., Giocoli, A., Lapenna, V., and Stabile, T. A.: Robust identification of periodic behavior in the time dynamics of short seismic series: the case of seismicity induced by Pertusillo Lake, southern Italy, Stoch. Env. Res. Risk A., 29, 1437-1446, https://doi.org/10.1007/s00477-014-0980-6, 2015.

Valoroso, L., Improta, L., Chiaraluce, L., Di Stefano, R., Ferranti, L., Govoni, A., and Chiarabba, C.: Active faults and induced seismicity in the Val d'Agri area (southern Apennines, Italy), Geophys. J. Int., 178, 488-502, https://doi.org/10.1111/j.1365246X.2009.04166.x, 2009.
Vlček, J., Eisner, L., Stabile, T. A., and Telesca, L.: Temporal relationship between injection rates and induced seismicity, Pure Appl. Geophys., 175, 2821-2835, https://doi.org/10.1007/s00024-017-1622-y, 2018.

Wcisło, M., Stabile, T. A., Telesca, L., and Eisner, L.: Variations of attenuation and $\mathrm{Vp} / \mathrm{Vs}$ ratio in the vicinity of wastewater injection: a case study of Costa Molina 2 well (High Agri Valley, Italy), Geophysics, 83, B25-B31, https://doi.org/10.1190/GEO2017-0123.1, 2018.

Weber, E., Convertito, V., Iannaccone, G., Zollo, A., Bobbio, A., Cantore, L., Corciulo, M., Di Crosta, M., Elia, L., Martino, C., Romeo, A., and Satriano, C.: An Advanced Seismic Network in the Southern Apennines (Italy) for Seismicity Investigations and Experimentation with Earthquake Early Warning, Seismol. Res. Lett. 78, 622-634, https://doi.org/10.1785/gssrl.78.6.622, 2007.

Withers, M. M., Aster, R. C., Young, C. J., and Chael, E. P.: Highfrequency analysis of seismic background noise as a function of wind speed and shallow depth, B. Seismol. Soc. Am., 86, 1507$1515,1996$.

Young, C. J., Chael, E. P., Zagar, D. A., and Carter, J. A.: Variations in noise and signal levels in a pair of deep boreholes near Amarillo, Texas, B. Seismol. Soc. Am., 84, 1593-1607, 1994.

Zheng, X. and McMechan, G. A.: Two methods for determining geophone orientations from VSP data, Geophysics, 71, V87V97, 2006. 